\title{
A quantitative method for sizing hyaluronan and other glycosaminoglycans on surfaces
}

\author{
Sumitra Srimasorn ${ }^{1,2, \#}$, Luke Souter ${ }^{1, \#}$, Dixy E. Green ${ }^{3}$, Lynda Djerbal ${ }^{1}$, Ashleigh \\ Goodenough $^{1,2}$, James A. Duncan ${ }^{1}$, Abigail R. E. Roberts ${ }^{1,2}$, Xiaoli Zhang ${ }^{1,2}$, Delphine \\ Débarre $^{4}$, Paul L. DeAngelis ${ }^{3}$, Jessica C. F. Kwok ${ }^{1,5,}{ }^{*}$, Ralf P. Richter ${ }^{1,2, *}$ \\ ${ }^{1}$ School of Biomedical Sciences, Faculty of Biological Sciences, University of Leeds, Leeds LS2 9JT, United \\ Kingdom. \\ ${ }^{2}$ School of Physics and Astronomy, Faculty of Engineering and Physical Sciences, Astbury Centre for \\ Structural Molecular Biology, and Bragg Centre for Materials Research, University of Leeds, Leeds LS2 9JT, \\ United Kingdom. \\ ${ }^{3}$ Department of Biochemistry and Molecular Biology, University of Oklahoma Health Sciences Center, \\ Oklahoma City, OK 73126, USA. \\ ${ }^{4}$ Université Grenoble-Alpes, CNRS, LIPhy, 38000 Grenoble, France. \\ 5 Institute of Experimental Medicine, Czech Academy of Sciences, Vídeňská, 1083 Prague, Czech Republic. \\ \# These authors contributed equally. \\ * Corresponding authors
}


bioRxiv preprint doi: https://doi.org/10.1101/2022 02 28.482386. this version posted March 1 2022. The copyright holder for this preprint (which was not certified by peer review) is the author/funder, who has granted bioRxiv a license to display the preprint in perpetuity. It is made available under aCC-BY-NC-ND 4.0 International license.

\section{Abstract:}

Hyaluronan ( $\mathrm{HA})$ is a major component of peri- and extra-cellular matrices and plays important roles in many biological processes such as cell adhesion, proliferation and migration. The abundance, size distribution and presentation of HA dictate its biological effects and are also useful indicators of pathologies and disease progression. Methods to assess the molecular mass of soluble HA and other glycosaminoglycans (GAGs) are well established. In many biological and technological settings, however, GAGs are displayed on surfaces, and methods to obtain the size of surface-attached GAGs are lacking. Here, we present a method to size HA that is end-attached to surfaces. The method is based on the quartz crystal microbalance with dissipation monitoring (QCM-D) and exploits that the softness and thickness of films of grafted HA increase with HA size. These two quantities are sensitively reflected by the ratio of the dissipation shift $(\Delta D)$ and the negative frequency shift ($\Delta f$ ) measured by QCM-D upon the formation of HA films. Using a series of size-defined HA preparations, ranging in size from a tetrasaccharide to a $1 \mathrm{MDa}$ polysaccharide, we establish a standard curve of the $\Delta D /-\Delta f$ ratio as a function of HA size. We demonstrate that the standard curve can be used to determine the mean size of $\mathrm{HA}$, as well as other GAGs, such as chondroitin sulfate and heparan sulfate, of preparations of previously unknown size in the range from 1 to $500 \mathrm{kDa}$, and with a resolution better than $10 \%$. For polydisperse samples, our analysis shows that the process of surface-grafting preferentially selects smaller GAG chains, and thus reduced the average size of GAGs that are immobilised on surfaces comparative to the original solution sample. Our results establish a quantitative method to size HA and other GAGs grafted on surfaces, and also highlight the importance of sizing GAGs directly on surfaces. The method should be useful for the development and quality control of GAG-based surface coatings in a wide range of research areas, from molecular interaction analysis to biomaterials coatings.

Keywords: Hyaluronan; glycosaminoglycan; quartz crystal microbalance; biointerfaces 
bioRxiv preprint doi: https://doi.org/10.1101/2022.02.28.482386; this version posted March 1, 2022. The copyright holder for this preprint (which was not certified by peer review) is the author/funder, who has granted bioRxiv a license to display the preprint in perpetuity. It is made available under aCC-BY-NC-ND 4.0 International license.

\section{Introduction}




\section{Materials and methods}

\subsection{Materials}

Lyophilized 1,2-dioleoyl-sn-glycero-3-phosphocholine (DOPC) and 1,2-dioleoyl-sn-glycero-3phosphoethanolamine-N-(Cap Biotinyl) (DOPE-cap-B) were purchased from Avanti Polar Lipids (Alabaster, USA). Lyophilised streptavidin (SAv) was purchased from Sigma-Aldrich.

Quasi-monodisperse size-defined hyaluronan, either plain ( $\mathrm{HA}$ ) or with a biotin tag at the reducing end (HA-b), was supplied as lyophilized powder from Hyalose (Oklahoma City, USA) or custom made as described previously [1]. Quasi-monodisperse size-defined heparosan (Hep-b) and chondroitin (CO-b) with a biotin tag at their reducing ends were custom made for this study using synchronized, stoichiometrically controlled chemoenzymatic reactions. For HEP-b, a heparosan trisaccharide amine derivative was extended with recombinant MBP-PmHS1 synthase using UDP-GIcNAc and UDP-GICA (Sigma) [2]. For CO-b, a HA tetrasaccharide amine [1] was extended with recombinant PmCS1-704 synthase [3]) using UDP-GalNAc and UDP-GIcA [4, 5]. These amine-tagged GAGs were biotinylated with biotin-LC-sulfoNHS reagent (Thermo) at 30x molar excess in 50 mM HEPES, pH 7.2 overnight. The target GAG-biotin polymer was then purified by ethanol precipitation (2.5 volumes, $0.1 \mathrm{M} \mathrm{NaCl}$ final concentration) and repeated ultrafiltration against water in a $3 \mathrm{kDa} \mathrm{MWCO}$ spin-unit (Millipore). Size-defined heparan sulfate (HS-b) oligosaccharides with a biotin tag at their reducing end were custom made as described previously [6]. See Table 1 for details and references regarding size-defined GAGs.

Table 1. Size-defined GAG samples used in this study.

\begin{tabular}{|c|c|c|c|c|c|}
\hline $\begin{array}{c}\text { GAG } \\
\text { Sample }\end{array}$ & $M_{\mathrm{w}}(\mathrm{kDa})^{\text {a) }}$ & $n_{\mathrm{ds}}{ }^{b)}$ & $\begin{array}{c}\text { PDI } \\
\left(M_{w} / M_{n}\right)\end{array}$ & Linker from GAG to biotin f) & $\begin{array}{l}\text { Provider / } \\
\text { Reference }\end{array}$ \\
\hline HAdp4-b & 0.8 & 2 & $1.0^{\mathrm{e})}$ & $=\mathrm{N}-\mathrm{O}-\mathrm{CH}_{2}-\mathrm{CO}-\mathrm{NH}-\left(\mathrm{CH}_{2}\right)_{2}-\mathrm{EG}_{3}-\mathrm{CH}-\mathrm{NH}-\mathrm{CO}-\left(\mathrm{CH}_{2}\right)_{4}-$ & [6] \\
\hline HAdp10-b & 2.0 & 5 & $1.0^{\mathrm{e})}$ & $=\mathrm{N}-\mathrm{O}-\mathrm{CH}_{2}-\mathrm{CO}-\mathrm{NH}-\left(\mathrm{CH}_{2}\right)_{2}-\mathrm{EG}_{3}-\mathrm{CH}-\mathrm{NH}-\mathrm{CO}-\left(\mathrm{CH}_{2}\right)_{4}-$ & [6] \\
\hline HAdp15-b & 3.0 & 7.5 & $1.0^{\mathrm{e})}$ & $-\mathrm{O}-\left(\mathrm{CH}_{2}\right)_{3}-\mathrm{S}-\left(\mathrm{CH}_{2}\right)_{2}-\mathrm{NH}-\mathrm{CO}-\left(\mathrm{CH}_{2}\right)_{4}-$ & {$[6,7]$} \\
\hline HA10-b & $13 \pm 1$ & $32.5 \pm 2^{c)}$ & & $-\mathrm{NH}-\mathrm{CO}-\left(\mathrm{CH}_{2}\right)_{5}-\mathrm{NH}-\mathrm{CO}-\left(\mathrm{CH}_{2}\right)_{4}-$ & [1] \\
\hline HA30-b & $38 \pm 2$ & $95 \pm 5^{c)}$ & & $-\mathrm{NH}-\mathrm{CO}-\left(\mathrm{CH}_{2}\right)_{5}-\mathrm{NH}-\mathrm{CO}-\left(\mathrm{CH}_{2}\right)_{4-}$ & [1] \\
\hline HA50-b & $58 \pm 3$ & $145 \pm 8^{c)}$ & $1.007^{d)}$ & $-\mathrm{NH}-\mathrm{CO}-\left(\mathrm{CH}_{2}\right)_{5}-\mathrm{NH}-\mathrm{CO}-\left(\mathrm{CH}_{2}\right)_{4}-$ & Hyalose [1] \\
\hline HA100-b & $100 \pm 5$ & $250 \pm 13$ & $1.011^{\mathrm{d})}$ & $-\mathrm{NH}-\mathrm{CO}-\left(\mathrm{CH}_{2}\right)_{5}-\mathrm{NH}-\mathrm{CO}-\left(\mathrm{CH}_{2}\right)_{4}-$ & [1] \\
\hline HA300-b & $317 \pm 16$ & $793 \pm 40^{c)}$ & $1.03^{d)}$ & $-\mathrm{NH}-\mathrm{CO}-\left(\mathrm{CH}_{2}\right)_{5}-\mathrm{NH}-\mathrm{CO}-\left(\mathrm{CH}_{2}\right)_{4-}$ & {$[1]$} \\
\hline HA500-b & $520 \pm 26$ & $1300 \pm 65^{c)}$ & & $-\mathrm{NH}-\mathrm{CO}-\left(\mathrm{CH}_{2}\right)_{5}-\mathrm{NH}-\mathrm{CO}-\left(\mathrm{CH}_{2}\right)_{4}-$ & Hyalose [1] \\
\hline HA1000-b & $838 \pm 42$ & $2095 \pm 105^{c)}$ & $1.003^{d)}$ & $-\mathrm{NH}-\mathrm{CO}-\left(\mathrm{CH}_{2}\right)_{5}-\mathrm{NH}-\mathrm{CO}-\left(\mathrm{CH}_{2}\right)_{4-}$ & Hyalose [1] \\
\hline HA250 & $273 \pm 14$ & $683 \pm 35^{c)}$ & & - & Hyalose [1] \\
\hline $\mathrm{co-b}$ & $276 \pm 14$ & $690 \pm 35^{c)}$ & $1.006^{\mathrm{d})}$ & $-\mathrm{NH}-\mathrm{CO}-\left(\mathrm{CH}_{2}\right)_{5}-\mathrm{NH}-\mathrm{CO}-\left(\mathrm{CH}_{2}\right)_{4}-$ & {$[3,4]$} \\
\hline Hep-b & $100 \pm 5$ & $250 \pm 13^{c)}$ & & $-\mathrm{NH}-\mathrm{CO}-\left(\mathrm{CH}_{2}\right)_{5}-\mathrm{NH}-\mathrm{CO}-\left(\mathrm{CH}_{2}\right)_{4-}$ & [2] \\
\hline Hep-b & $307 \pm 16$ & $768 \pm 39^{c)}$ & $1.012^{d)}$ & $-\mathrm{NH}-\mathrm{CO}-\left(\mathrm{CH}_{2}\right)_{5}-\mathrm{NH}-\mathrm{CO}-\left(\mathrm{CH}_{2}\right)_{4-}$ & {$[2]$} \\
\hline HSdp6-b & & 3 & $1.0^{\mathrm{e})}$ & $=\mathrm{N}-\mathrm{O}-\mathrm{CH}_{2}-\mathrm{CO}-\mathrm{NH}-\left(\mathrm{CH}_{2}\right)_{2}-\mathrm{EG}_{3}-\mathrm{CH}-\mathrm{NH}-\mathrm{CO}-\left(\mathrm{CH}_{2}\right)_{4}-$ & {$[6]$} \\
\hline HSdp8-b & & 4 & $1.0^{\mathrm{e})}$ & $=\mathrm{N}-\mathrm{O}-\mathrm{CH}_{2}-\mathrm{CO}-\mathrm{NH}-\left(\mathrm{CH}_{2}\right)_{2}-\mathrm{EG}_{3}-\mathrm{CH}-\mathrm{NH}-\mathrm{CO}-\left(\mathrm{CH}_{2}\right)_{4}-$ & {$[6]$} \\
\hline HSdp10-b & & 5 & $1.0^{\mathrm{e})}$ & $=\mathrm{N}-\mathrm{O}-\mathrm{CH}_{2}-\mathrm{CO}-\mathrm{NH}-\left(\mathrm{CH}_{2}\right)_{2}-\mathrm{EG}_{3}-\mathrm{CH}-\mathrm{NH}-\mathrm{CO}-\left(\mathrm{CH}_{2}\right)_{4}-$ & {$[6]$} \\
\hline HSdp12-b & & 6 & $1.0^{\mathrm{e})}$ & $=\mathrm{N}-\mathrm{O}-\mathrm{CH}_{2}-\mathrm{CO}-\mathrm{NH}-\left(\mathrm{CH}_{2}\right)_{2}-\mathrm{EG}_{3}-\mathrm{CH}-\mathrm{NH}-\mathrm{CO}-\left(\mathrm{CH}_{2}\right)_{4}-$ & {$[6]$} \\
\hline
\end{tabular}

a) $M_{w}$ as per manufacturer's specifications (excluding the mass of the biotin and linker). Based on the polydispersity index (PDI) for most polysaccharides, errors for all size-defined GAG polysaccharides were conservatively estimated to $\pm 5 \%$. ${ }^{\text {b) }}$ Number of disaccharides per chain, $n_{\mathrm{ds} .}$. ${ }^{\text {c) }}$ Calculated from $M w$ and a molecular mass of 400 Da per disaccharide. d) PDI for polysaccharides determined by SEC-MALLS, as per manufacturer's specification. ${ }^{\text {e) }}$ Oligosaccharides were purified by size, and are assumed to have a PDI close to 1. f) Biotin was conjugated to $\mathrm{C}_{1}$ of $\mathrm{N}$-acetylglucosamine (for HA-b and HS-b) and $\mathrm{N}$-acetylgalactosamine (for $\mathrm{CO}$ b) at the reducing end of the GAGs; EG - ethylene glycol.

Preparations of chondroitin sulfate (CS), including with varying sulfation levels (CS-A, CS-C, CS-D and CS-E), dermatan sulfate (DS) and heparan sulfate (HS) (all extracted and purified from animal tissues), and HA (purified from microbial fermentation and size fractionated), were purchased from commercial providers; see 
bioRxiv preprint doi: https://doi org/10.1101/2022.02.28.482386; this version posted March 1 , 2022. The copyright holder for this preprint (which was not certified by peer review) is the author/funder, who has granted bioRxiv a license to display the preprint in perpetuity. It is made available under aCC-BY-NC-ND 4.0 International license.

Table 2 for details. These preparations, which are known to show a rather large size distribution, were biotinylated at their reducing end by oxime ligation; see Supplementary Methods for details.

Table 2. Polydisperse GAG polysaccharide samples used in this study.

\begin{tabular}{|c|c|c|c|c|}
\hline GAG sample & Mean $M_{w}(k D a)^{a)}$ & $\begin{array}{c}\text { PDI }{ }^{\text {a) }} \\
\left(\mathrm{M}_{w} / \mathrm{M}_{\mathrm{n}}\right)\end{array}$ & Animal Source & $\begin{array}{c}\text { GAG provider }{ }^{\text {b) }} \\
\text { (catalogue number, or reference) }\end{array}$ \\
\hline $\mathrm{pHA}-\mathrm{b}$ & 357 & & Microbial fermentation & Lifecore Biomedical (HA500K) [8] \\
\hline $\mathrm{pHS}-\mathrm{b}$ & 12 & 1.6 & Porcine intestinal mucosa & Celsus Laboratories [9] \\
\hline pCS-b & not provided & & Shark cartilage & Sigma-Aldrich (C4384) \\
\hline pCS-A-b & 16 & & Sturgeon notochord & Seikagaku (400658) \\
\hline pDS-b & 30 & & Porcine intestinal mucosa & Sigma-Aldrich (C3788) \\
\hline pCS-C-b & $60 \pm 20$ & & Shark cartilage & Amsbio (400675) \\
\hline pCS-D-b & 30 & & Shark cartilage & Amsbio (400676) \\
\hline pCS-E-b & $62.5 \pm 12.5$ & & Squid cartilage & Seikagaku (400678) \\
\hline
\end{tabular}

a) Mean $M_{w}$ and PDI as per manufacturer's specifications or reference provided, where available. ${ }^{\text {b) }}$ All samples were purchased without biotin tag, and biotinylated at the reducing end by oxime ligation (see Supplementary Methods for details).

\subsection{Sample preparation}

Working buffer for all QCM-D experiments consisted of 10 mM HEPES, pH 7.4, $150 \mathrm{mM} \mathrm{NaCl}$ prepared in ultrapure water $\left(\mathrm{uH}_{2} \mathrm{O}\right.$; resistivity $\left.18.2 \mathrm{M} \Omega \mathrm{cm}^{-1}\right)$.

Small unilamellar vesicles displaying biotin (b-SUVs) were prepared as previously described [10] with modifications. Briefly, lipids in chloroform were mixed at a ratio of 95 mol-\% DOPC and 5 mol-\% DOPE-cap-B at a total amount of $5 \mu \mathrm{mol}$, and dried under a stream of nitrogen gas followed by drying in a vacuum desiccator for $2 \mathrm{~h}$. The lipid mixture was re-suspended in working buffer at $2 \mathrm{mg} \mathrm{mL}^{-1}$, and homogenised by five cycles of freezing, thawing and vortexing. To obtain SUVs, the lipid suspension was subjected to tip sonication in pulse mode ( $1 \mathrm{~s}$ on / $1 \mathrm{~s}$ off) for $30 \mathrm{~min}$ with refrigeration. The SUV suspension was then centrifuged at $12,100 \times g$ for $10 \mathrm{~min}$ to remove titanium debris (originating from the sonicator tip), and stored at $4^{\circ} \mathrm{C}$ under nitrogen gas until use.

Lyophilized SAv was dissolved in $\mathrm{uH}_{2} \mathrm{O}$ at $1 \mathrm{mg} \cdot \mathrm{mL}^{-1}$ and stored at $-20{ }^{\circ} \mathrm{C}$ until use. GAGs were resuspended in $\mathrm{uH}_{2} \mathrm{O}$. GAGs of $\mathrm{Mw}_{w}<250 \mathrm{kDa}$ were vortexed for rapid sample homogenisation; larger GAGs were not vortexed but incubated at $4{ }^{\circ} \mathrm{C}$ for $2 \mathrm{~h}$ without shaking to avoid chain degradation owing to mechanical shear. All GAG samples were stored at $-20^{\circ} \mathrm{C}$ until use.

\subsection{Quartz crystal balance with dissipation monitoring (QCM-D)}

QCM-D measurements on silica-coated sensors (QSX303; Biolin Scientific, Västra Frölunda, Sweden) were performed with a Q-Sense E4 system (Biolin Scientific) equipped with 4 independent flow modules, connected to a syringe pump (Legato; World Precision Instruments, Stevenage, UK) to deliver a fluid flow of 10 to $20 \mu \mathrm{L} \cdot \mathrm{min}^{-1}$. The working temperature was set to $24^{\circ} \mathrm{C}$. Changes in resonance frequency $\left(\Delta f_{i}\right)$ and dissipation $\left(\Delta D_{i}\right)$ were acquired from six overtones $\left(i=3,5,7,9,11\right.$ and 13 , corresponding to resonance frequencies of $f_{i} \approx$ $5,15,25,35,45,55$ and $65 \mathrm{MHz}$ ). Results from overtone $i=3$ are presented unless stated otherwise, and frequency shifts are presented normalised by the overtone number $\left(\Delta f=\Delta f_{i} / i\right)$. All other overtones provided qualitatively similar data.

\subsection{Polyacrylamide gel electrophoresis (PAGE)}

GAG samples were analysed by PAGE for independent confirmation of their size and size distribution. Each GAG sample of molecular mass $>250 \mathrm{kDa}(0.125 \mu \mathrm{g}$ for size-defined samples, $3 \mu \mathrm{g}$ for polydisperse samples) was mixed with FACE loading agent (a mixture of glycerol and $\mathrm{uH}_{2} \mathrm{O}$ at a ratio of $1: 3 \mathrm{v} / \mathrm{v}$, and $1 \mathrm{mg} \cdot \mathrm{mL}^{-1}$ 
bioRxiv preprint doi: https://doi.org/10.1101/2022.02 28.482386; this version posted March 1, 2022. The copyright holder for this preprint (which was not certified by peer review) is the author/funder, who has granted bioRxiv a license to display the preprint in perpetuity. It is made available under aCC-BY-NC-ND 4.0 International license.

bromophenol blue) and $1 \times$ Tris-borate buffer ( $0.05 \mathrm{M}$ Trizma base, $0.06 \mathrm{M}$ boric acid, $\mathrm{pH} 8.3$ ) at volumes of 10 $\mu \mathrm{L}, 3 \mu \mathrm{L}$ and $2 \mu \mathrm{L}$, respectively. GAG polysaccharides of lower molecular mass $(1 \mu \mathrm{g}$ for size-defined samples, 3 $\mu \mathrm{g}$ for polydisperse samples) were mixed with a different FACE loading agent (a mixture of glycerol, DMSO and $\mathrm{uH}_{2} \mathrm{O}$ at a ratio of 1:2:7 v/v, and $1 \mathrm{mg} \cdot \mathrm{mL}^{-1}$ bromophenol blue) and $2 \times$ Tris-borate buffer at volumes of $10 \mu \mathrm{L}, 3$ $\mu \mathrm{L}$ and $2 \mu \mathrm{L}$, respectively. Samples and appropriate molecular mass markers (HA ladder; Hyalose) were loaded into a Tris-borate gel and ran at $300 \mathrm{~V}$ in $2 \times$ Tris-borate buffer at $4{ }^{\circ} \mathrm{C}$. Gels were fixed with $10 \%$ ethanol in $1 \times$ Tris-borate buffer for $30 \mathrm{~min}$ prior to staining with Alcian Blue solution (0.4\% w/v Alcian Blue 8GX (Sigma Aldrich), $40 \% v / v$ methanol and $8 \% v / v$ acetic acid in $\mathrm{uH}_{2} \mathrm{O}$ ) for visualization of GAGs. De-staining was performed with an aqueous solution containing $40 \% v / v$ methanol and $8 \% v / v$ acetic acid. 
bioRxiv preprint doi: https://doi.org/10.1101/2022.02.28.482386; this version posted March 1, 2022. The copyright holder for this preprint (which was not certified by peer review) is the author/funder, who has granted bioRxiv a license to display the preprint in perpetuity. It is made available under aCC-BY-NC-ND 4.0 International license.

\section{Results}

\subsection{GAG brushes provide defined anchorage, suitable for GAG sizing on surfaces}

Here, we introduce QCM-D as a method to size GAG chains that are anchored with one end to a planar surface. GAGs with a biotin tag at the reducing end (GAG-b) were anchored to a streptavidin (SAv)-coated supported lipid bilayer (SLB). The anchorage approach is illustrated in Figure 1a (left), is well established [11, 12], and provides for site-specific attachment (i.e., 'grafting' via biotin) without secondary interactions of the GAG chains with the SLB/SAv-coated surface.
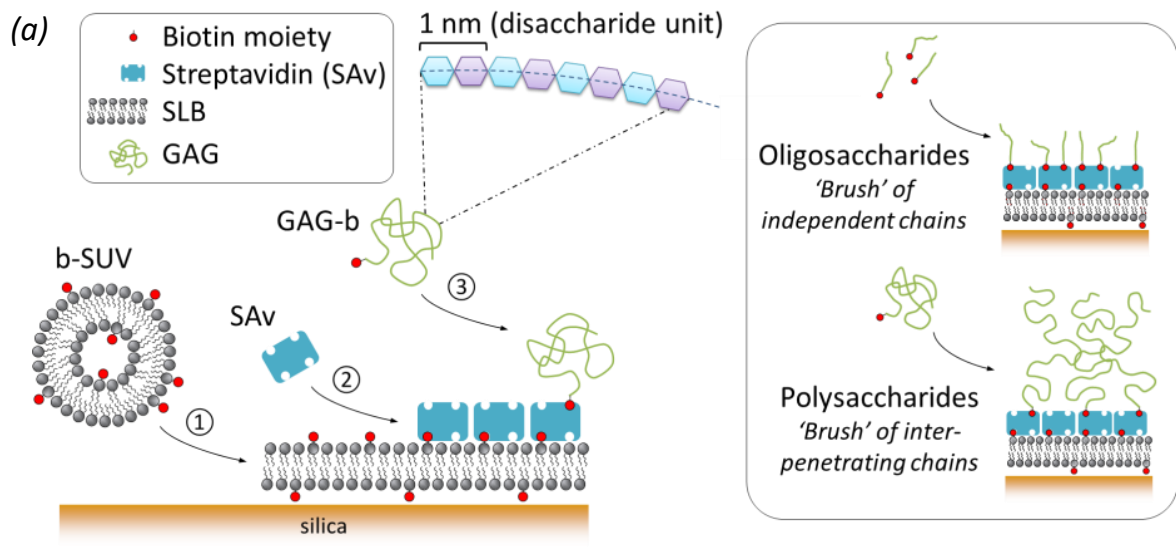

(b)

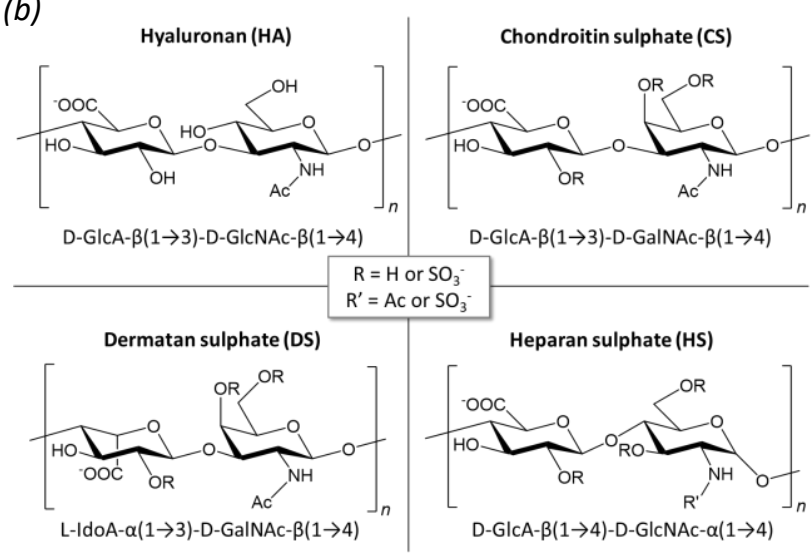

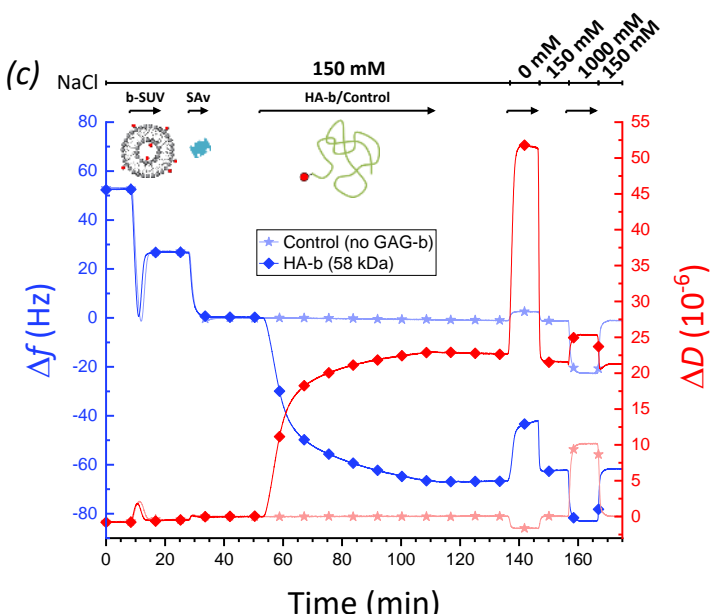

Figure 1. Experimental setup for GAG-sizing by QCM-D. (a) Schematic displaying the surface functionalisation steps: (1) Formation of a supported lipid bilayer (SLB) on the quartz crystal sensor surface (silica) from small unilamellar vesicles containing 5 mol-\% biotinylated lipids (b-SUVs); (2) Formation of a streptavidin (SAv) monolayer (reference surface); (3) Grafting of GAGs of various sizes via a biotin their reducing end (GAG-b). All molecules are drawn roughly to scale, except the GAG polysaccharides for which the linear dimensions can exceed SAv by 10-fold and more. (b) Disaccharide unit structures of the GAG types studied, including possible sulfations (for CS, DS and HS; additionally, GlcA units of HS may be epimerised into IdoA). (c) Representative QCM-D experiment monitoring all typical incubation steps. Shifts in frequency ( $\Delta f$; blue lines) and dissipation $(\Delta D$; red lines) for the third overtone $(i=3)$ are shown for an experiment with HA-b (58 kDa; lines with diamonds) and for an experiment without any GAG-b (control; lines with stars). The start and the duration of sample incubation steps are indicated by the arrows above the graph; along with the $\mathrm{NaCl}$ concentration. Incubation conditions: buffer - $10 \mathrm{mM} \mathrm{HEPES,} \mathrm{pH} \mathrm{7.4,} \mathrm{with} \mathrm{NaCl}$ as indicated; b-SUVs $-50 \mu \mathrm{g} / \mathrm{mL}$; SAv - $20 \mu \mathrm{g} / \mathrm{mL}$; HA-b (58 kDa) - $5 \mu \mathrm{g} / \mathrm{mL}$. 
bioRxiv preprint doi: https://doi.org/10.1101/2022.02.28.482386; this version posted March 1, 2022. The copyright holder for this preprint (which was not certified by peer review) is the author/funder, who has granted bioRxiv a license to display the preprint in perpetuity. It is made available under aCC-BY-NC-ND 4.0 International license.

The conformation of the GAG chains on the sensor depends on both GAG size and surface coverage. GAG oligosaccharides ( $\$ 20$ monosaccharide units) have a contour length ( $1 \mathrm{~nm}$ per disaccharide in the chain) comparable to the persistence length (a measure of chain flexibility; $4.1 \mathrm{~nm}$ for HA [13], and likely similar in magnitude for other GAGs, at physiological salt concentration and $\mathrm{pH}$ ) and therefore will present extended yet dynamically bending conformations in solution. Surface grafting is not expected to substantially affect the conformation of these chains, i.e., they will adopt a range of random orientations, and hardly interact with each other even at the highest attainable surface densities (Figure 1a, upper right). On the other hand, GAG polysaccharides ( $\gtrsim 20$ monosaccharide units) have a much larger contour length and thus form extended 'random coils' in solution. When grafted to the surface at low coverage, the random coil conformation is largely preserved, but chains will interpenetrate and repel each other (due to the negative charges on the numerous GlcA monosaccharides) at sufficiently high grafting density, thus inducing preferential chain stretching away from the surface (Figure 1a, lower right) [14-16]. We here refer to films of grafted and stretched oligosaccharide/polysaccharide chains as GAG 'brushes', consistent with established terminology for grafted polymers [17].

We monitored all surface functionalisation steps and the brush formation process for various GAG types and sizes (Figure 1b, Table 1 and Table 2) using QCM-D (Figure 1c) at close-to-physiological pH (7.4) and ionic strength $(150 \mathrm{mM} \mathrm{NaCl})$, to ascertain the surface preparation proceeded correctly and to quantify the QCM-D responses (frequency shifts, $\Delta f$, and dissipation shifts, $\Delta D$ ) upon GAG-b binding. For any of the incubation steps, a decrease in $\Delta f$ (Figure 1c, blue lines) indicates an increase in the sensed mass on the surface (which includes hydrodynamically coupled water) while the associated $\Delta D$ changes (Figure 1c, red lines) reflect on the softness of the biomolecular films $[11,18]$. The QCM-D responses evidenced the formation of a proper SLB (Figure 1c, 7 - $17 \mathrm{~min}$ ) and a densely packed monolayer of SAv (Figure 1c, 27 - $33 \mathrm{~min}$ ) as a robust platform for GAG brush formation (see refs. $[19,20]$ and Supplementary Methods for detailed analyses of these processes). As a whole, the SAv-on-SLB film generates very little dissipation shift, i.e., it is essentially sensed as a rigid film by QCM-D. Subsequent incubation with GAGs with biotin tag consistently led to an additional decrease in frequency and a marked increase in dissipation, as exemplified in Figure 1c (lines with diamonds, 53-111 min) for HA-b with a molecular mass of $58 \mathrm{kDa}$. These shifts were absent in a control experiment utilising plain HA (273 kDa) lacking a biotin tag (Figure S1, lines with stars), demonstrating that GAGs attach to the surface exclusively via specific biotin-SAv interactions. Moreover, the GAG brushes were stable over time, as seen by the absence of further frequency and dissipation shifts upon rinsing in working buffer (Figure 1c; 111 - 137 min).

\subsection{Size-defined HAs reveal how steric hindrance of GAG brushes influences the magnitude of QCM-D responses}

To establish how sensitive QCM-D is to GAG size and therefore suitable for sizing GAG chains, we compared a set of $10 \mathrm{HA}-\mathrm{b}$ samples with well-defined sizes ranging from 2 disaccharides $\left(n_{\mathrm{ds}}=2\right)$ to $838 \mathrm{kDa}\left(n_{\mathrm{ds}}\right.$ $\approx 2100$; Table 1). The full set of QCM-D data are shown in Figure S2. We chose HA because it is the simplest of all GAG types (i.e., with a perfectly regular disaccharide structure) and because size-defined samples of HA were available over a very large size range. Polyacrylamide gel electrophoresis showed all polysaccharide samples as defined and narrow bands (Figure S3), indicating no or very little contamination with low molecular mass residues that could have resulted from degradation during handling.

We first inspected the QCM-D responses at maximal HA-b binding (i.e., at the end of the HA incubation process; Figure 2). Interestingly, both $\Delta f_{\min }$ nor $\Delta D_{\max }$ varied non-monotonically with $\mathrm{HA}$ size: the magnitudes of $\Delta f_{\min }$ and $\Delta D_{\max }$ were largest at an intermediate size $\left(\Delta f_{\min }=-72 \mathrm{~Hz}\right.$ for $\mathrm{HA}-\mathrm{b} 38 \mathrm{kDa}$, and $\Delta D_{\max }=23 \times 10^{-6}$ for $\mathrm{HA}-$ b $58 \mathrm{kDa}$, respectively), but decreased towards smaller and larger sizes. The size-dependent trends observed can be attributed to two opposing effects of GAG size. On the one hand, the QCM-D response per chain is expected to increase with size owing to the increased mass (and hydrodynamically coupled solvent) of larger chains, at comparable grafting densities. On the other hand, the chain size negatively impacts the grafting density that can be attained in the experiment; the GAG chains on forming a brush impose a steric barrier to the access of 
additional chains to the surface, and thus gradually reduce the binding rate as the brush becomes denser [11, 21]. This barrier effect is expected to be negligible for very short oligosaccharide chains yet very pronounced for long polysaccharide chains due to the larger volume that they occupy and the larger steric hindrance they exert.

\section{Molecular mass (kDa)}

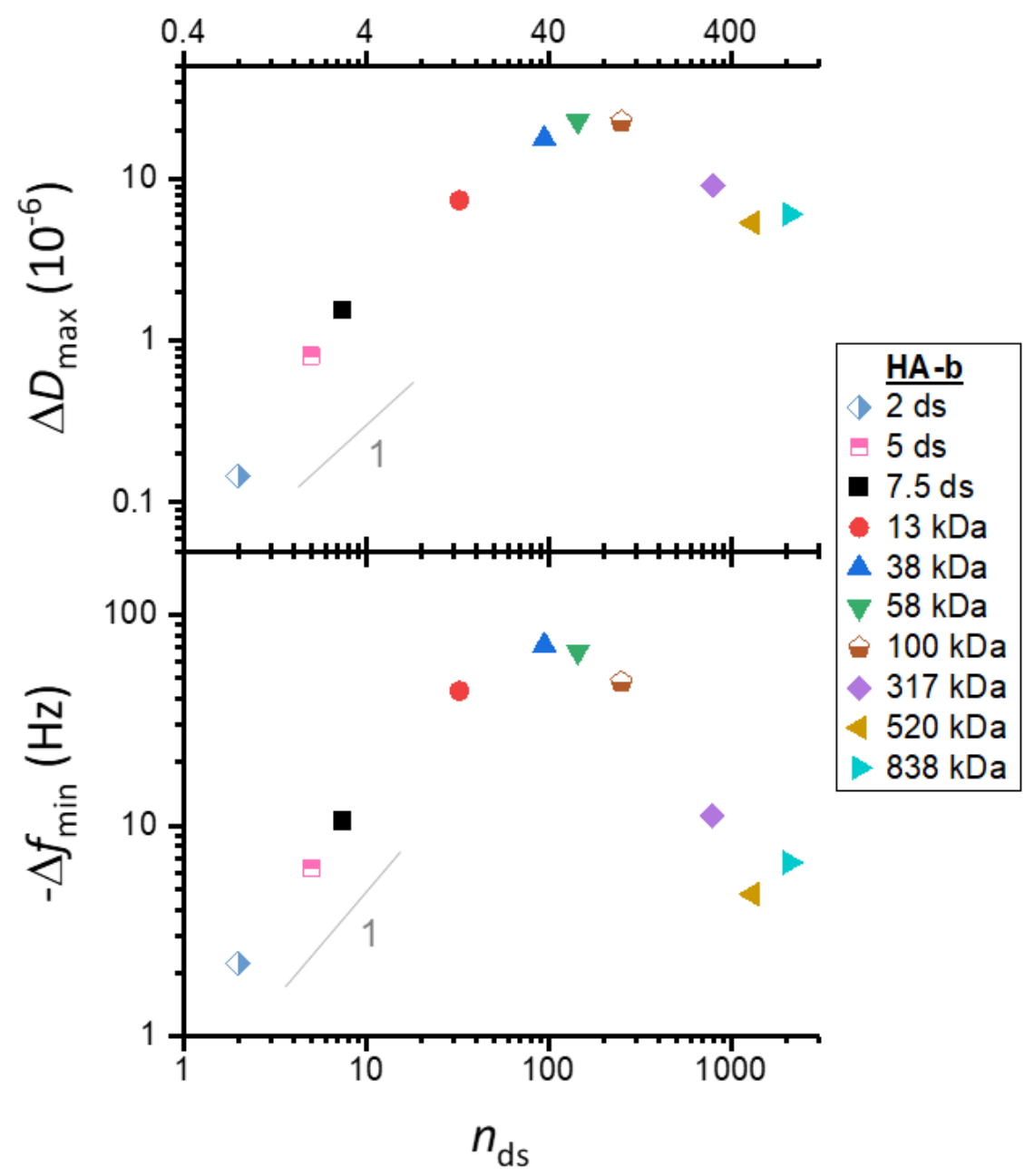

Figure 2. Maximal QCM-D responses vary non-monotonically with HA size. Double-logarithmic plots with shifts in dissipation $\left(\Delta D_{\max }\right)$ and frequency $\left(-\Delta f_{\min } ; i=3\right)$ at maximum GAG binding as a function of the mean number of disaccharides, $n_{\mathrm{ds}}$, per chain. Estimated experimental uncertainties (accounting for baseline drift upon $\mathrm{HA}$ binding: $0.67 \times 10^{-6}$ for $\Delta D$ and $0.33 \mathrm{~Hz}$ for $\Delta f$ per hour) are smaller than the symbol size and not shown. Grey lines with a slope of one are shown for reference: $-\Delta f_{\min }$ increases roughly linearly with $\mathrm{HA}$ size for small $\mathrm{HA}$ sizes. Incubation conditions: $\mathrm{HA}-\mathrm{b}$ oligosaccharides $(2,5$ and $7.5 \mathrm{ds})$ and $\mathrm{HA}-\mathrm{b}$ polysaccharides $(13,38,58$ and $317 \mathrm{kDa})$ $-5 \mu \mathrm{g} / \mathrm{mL}$; HA-b $100 \mathrm{kDa}-10 \mu \mathrm{g} / \mathrm{mL}$; HA-b $520 \mathrm{kDa}$ and HA-b $838 \mathrm{kDa}-20 \mu \mathrm{g} / \mathrm{mL}$; see Figure S2 for original data.

Our data (Figure S2) are entirely consistent with longer saccharides exerting steric hindrance, as evidenced by reduced binding rates and lower grafting densities with increasing HA size. HA-b binding saturated within $10 \mathrm{~min}$ or less for all HA-b oligosaccharides ( $n_{\mathrm{ds}}=2,5$ and 7.5) and also for the smallest HA-b polysaccharide ( $13 \mathrm{kDa}, n_{\mathrm{ds}} \approx 33$ ) tested, indicating that these short chains readily occupy all available biotin binding sites on the SAv monolayer. The binding site density for a similarly prepared surface was previously shown to be $7.8 \mathrm{pmol} / \mathrm{cm}^{2}$ [7], corresponding to a root-mean-square (rms) distance between GAG anchors of $d_{\mathrm{rms}}=4.6 \mathrm{~nm}$. In this regime, where the films are dense and thus relatively rigid, $-\Delta f_{\text {min }}$ increases roughly linearly with HA size (Figure 2). In contrast, the binding rate of all other HA-b chains gradually decreased with coverage 
and did not saturate during the incubation times selected in our experiments (40 to $60 \mathrm{~min}$ ). For the largest HAb chains tested ( 317,520 and $838 \mathrm{kDa}$ ), the barrier to binding increased to such an extent that binding virtually stalled after about 30 min of HA-b incubation. For HA-b (838 kDa), for example, we have previously reported rms distances between anchor points of $d_{\mathrm{rms}}>50 \mathrm{~nm}$ under conditions similar to the ones used here [22, 23], implying that grafting densities are more than 100 -fold reduced for the largest GAG chains compared to oligosaccharides. The reduced grafting densities also render the less dense brushes formed with the largest HAb chains softer (vide infra), and this characteristic further attenuates the QCM-D frequency shift.

In conclusion, the reduction in grafting density outweighs the mass effect of chain size on the QCM-D response. Moreover, the lack of monotonic trends makes the $\Delta f$ or $\Delta D$ values alone unsuitable for establishing a clear relationship (i.e., a standard curve) between GAG size and QCM-D response.

\subsection{The $\Delta D /-\Delta$ f ratio enables robust $H A$ sizing}

In light of the complexity in the dependence of HA-b size on the frequency and dissipation shifts when each parameter is analysed on their own, we instead explored the $\Delta D /-\Delta f$ ratio. The $\Delta D /-\Delta f$ ratio is a measure of the elastic compliance (or 'softness') for ultrathin yet homogenous films [24, 25]. In an alternative approach, Gizeli et al. demonstrated that the $\Delta D /-\Delta f$ ratio parallels changes in the intrinsic viscosity (a measure of molecular shape in the solution phase) of surface-grafted DNA chains, and that the $\Delta D /-\Delta f$ ratio is approximately independent of surface coverage [24, 26, 27]. Building on these findings, we hypothesised that this parameter could provide a simple approach to measure GAG size.

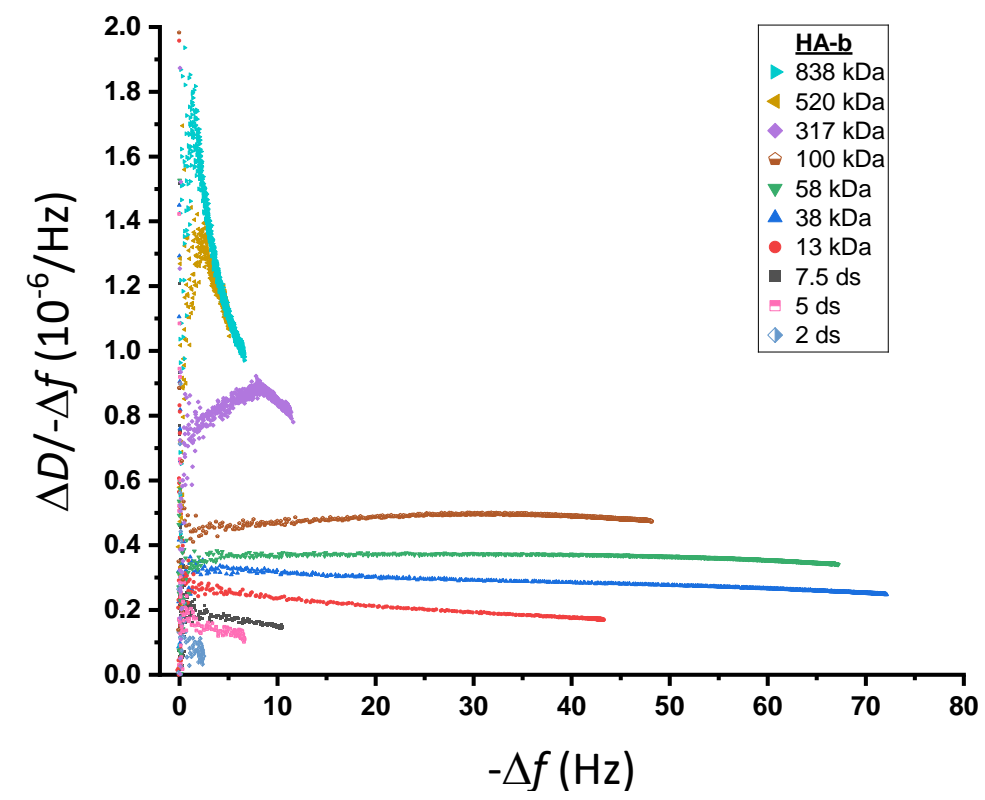

Figure 3. $\Delta D /-\Delta f$ analysis robustly discriminates HA sizes. Parametric plots of $\Delta D /-\Delta f v s .-\Delta f(i=3)$ during the formation of brushes of HA with defined sizes (as indicated with symbol and colour code; see Figure $\mathbf{S 2}$ for original data.

Using the QCM-D responses for each HA-b size, the $\Delta D /-\Delta f$ ratio was calculated and plotted as a function of the negative frequency shift (- $\Delta f$ ) which here serves as a proxy for relative surface coverage (Figure 3). A clear trend can be discerned, with the $\Delta D /-\Delta f$ ratio showing a pronounced increase as a function of HA size (for any given $-\Delta f$ value). We also noticed changes in the $\Delta D /-\Delta f$ ratio with surface coverage (i.e., as a function of $-\Delta f$, for any given HA size), although these were typically less pronounced than the dependence on size: for HA oligosaccharides and polysaccharides of intermediate sizes ( $\leq 58 \mathrm{kDa}$ ), only a weak monotonic decrease in $\Delta D /$ $\Delta f$ with $-\Delta f$ was generally noted. For HA chains of higher molecular weight ( $>58 \mathrm{kDa})$, coverage effects were more pronounced, with an initial increase preceding the phase of decreasing $\Delta D /-\Delta f$. Notably, the $\Delta D /-\Delta f$ ratios 
bioRxiv preprint doi: https:/doi.org/10.1101/2022.02 28.482386; this version posted March 1, 2022. The copyright holder for this preprint (which was not certified by peer review) is the author/funder, who has granted bioRxiv a license to display the preprint in perpetuity. It is made available under aCC-BY-NC-ND 4.0 International license.

for $\mathrm{HA}$ of 317,520 and $838 \mathrm{kDa}$ were comparable at the highest surface coverages but clearly distinct at low coverages. Thus, the sensitivity of the $\Delta D /-\Delta f$ ratio to HA size at low coverage provides a better distinction for sizing GAGs.

\subsection{Establishing a standard curve for sizing $H A$}

Having demonstrated that the $\Delta D /-\Delta f$ ratio is a sensitive predictor for HA size over a wide size range, we aimed to establish a standard curve for practical use in GAG sizing applications. Using $\Delta D /-\Delta f$ ratios at maximum polysaccharide coverage for size analysis is suboptimal, because the coverage varies between experiments with incubation conditions and these coverage variations impact on the $\Delta D /-\Delta f$ ratio (Figure 3 ). Hence, a specific target frequency for GAG sizing would be preferable.

We chose $-\Delta f=2.5 \mathrm{~Hz}$ for $\Delta D /-\Delta f$ ratio determination, which provides several benefits. First, the choice of a specific frequency eliminates the issue of coverage dependence in the $\Delta D /-\Delta f$ ratio, and thus enhances the robustness of the data. Second, the $\Delta D /-\Delta f$ ratio at $-\Delta f=2.5 \mathrm{~Hz}$ is accessible for all GAG sizes, from the shortest oligosaccharides to the longest polysaccharides. Third, it is a good balance that combines an acceptable signalto-noise ratio in the $\Delta D /-\Delta f$ values (noise becomes excessive as $-\Delta f$ approaches zero, as seen in Figure 3) with a minimal amount of sample and/or experimental time (which increase towards higher coverage, or $-\Delta f$ values).

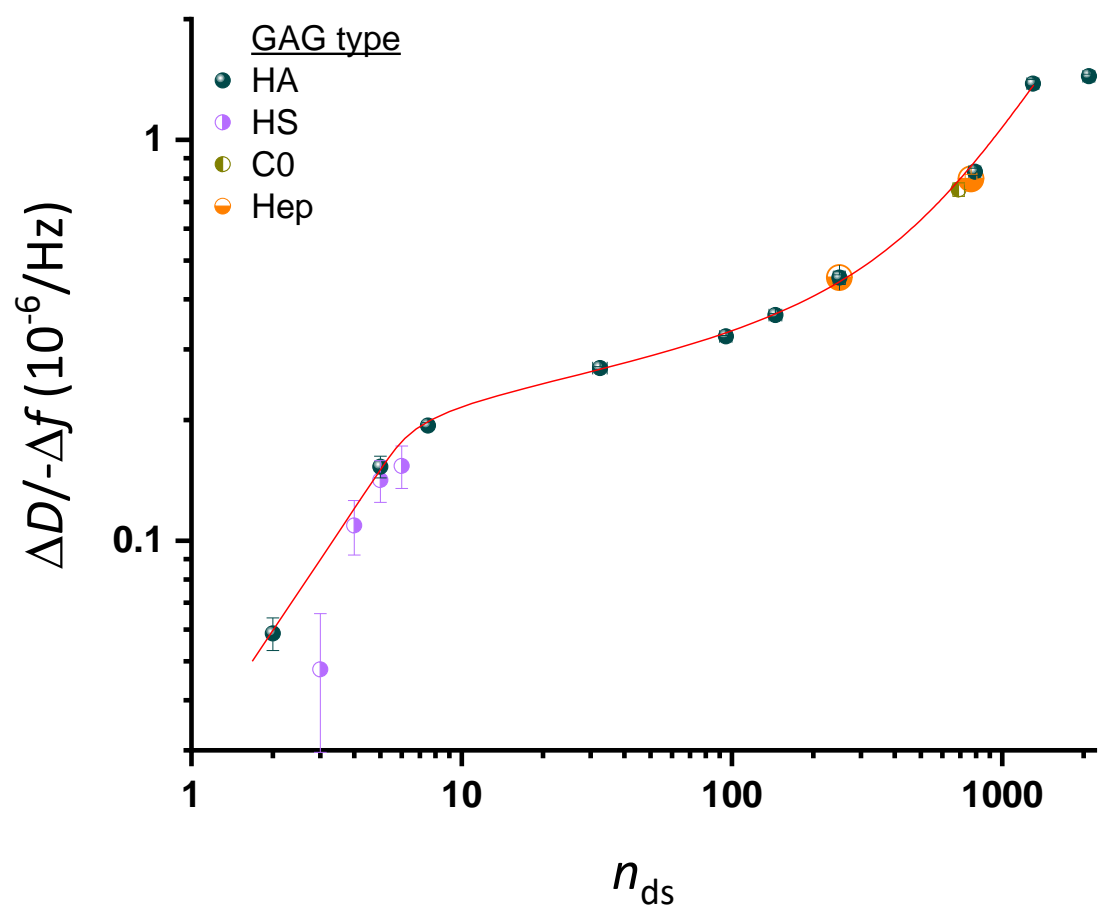

Figure 4. Standard curve for sizing $\mathrm{HA}$, and extension to other GAG types. Double logarithmic plot of $\Delta D /-\Delta f(i$ $=3$ ) at low GAG surface density $(-\Delta f=2.5 \mathrm{~Hz})$ as a function of the mean number of disaccharides per GAG-b chain, $n_{\mathrm{ds}}$ (mean $\pm 5 \%$, except for oligosaccharides which were taken to be pure in size, see Table 1). Data for all sizedefined HA-b samples (blue spheres) represent mean \pm standard error of the mean from between two and four independent experiments (see Figure $\mathbf{S 4}$ for details). The data for HA up to $n_{\mathrm{ds}}=1300$ are faithfully reproduced and interpolated by Equation 1 (red line), representing the standard curve for GAG sizing. Data for size-defined preparations of other GAG types (half-filled circles; see Figure $\mathbf{S 6}$ for original data) are also seen to map onto the standard curve: four heparan sulfate (HS-b; violet) oligosaccharides, two heparosan (Hep-b; orange) or one chondroitin (CO-b; dark yellow) polysaccharide. Symbols and error bars for non-HA GAGs represent individual experiments with the mean \pm standard deviation time-averaged over $-\Delta f$ values ranging between 2 and $3 \mathrm{~Hz}$. Data points for Hep-b (orange) are displayed with larger symbols than for HA-b and CO-b, to make them better visible behind the HA-b data at the similar molecular mass. 
Figure 4 shows the $\Delta D /-\Delta f$ ratio (at $-\Delta f=2.5 \mathrm{~Hz}$ ) as a function of $\mathrm{HA}$ size. The mean and the standard error of the mean (blue spheres with error bars) were here determined from between two and four independent experiments per HA size. The errors are generally small, indicating good reproducibility of the $\Delta D /-\Delta f$ ratio (see Figure $\mathbf{S 4}$ for results of all individual experiments). HA size is expressed in $n_{\mathrm{ds}}$.

As expected, a clear trend of $\Delta D /-\Delta f$ ratios monotonically increasing with HA size can be discerned. However, the $\Delta D /-\Delta f$ ratio dependence is rather complex: a sharp increase for oligosaccharides $\left(n_{\mathrm{ds}}=2\right.$ to 7.5$)$ is followed by a shallower slope for small and intermediate-sized polysaccharides (up to $n_{\mathrm{ds}}=800$ ), a renewed sharp increase between $n_{\mathrm{ds}}=800$ and 1300, and a plateau is effectively attained for the largest polysaccharides $\left(n_{\mathrm{ds}}>1300\right)$. The red line in Figure 4 corresponds to the function

$$
n_{\mathrm{ds}}=32.66\left(\frac{\Delta D}{-\Delta f} / \frac{10^{-6}}{\mathrm{~Hz}}\right)^{0.9907}\left[1+\frac{58.78}{1+\exp \left(2.291 \frac{\mathrm{Hz}}{10^{-6}} \frac{\Delta D}{-\Delta f}\right)^{-2.277}}\right]
$$

where the five numerical values were determined through fitting to the data for all HA sizes up to $n_{\mathrm{ds}}=1300$ $(520 \mathrm{kDa})$. The choice of this function was empirical (see Section 4.3 for a discussion of the physical origin of the curve shape) yet it reproduces the experimental data faithfully and thus provides a useful tool for data interpolation. Note that Equation 1 expresses $n_{\mathrm{ds}}$ as a function of $\Delta D /-\Delta f$, rather than vice versa, to facilitate the determination of the GAG size from an experimentally measured $\Delta D /-\Delta f$ value. The average (i.e., root-meansquare) deviation in $n_{\mathrm{ds}}$ between the experimental data and the interpolating fit (Figure S5) was below $2 \%$, and the maximal deviation was below 9\%, across the HA size range considered, indicating that Equation 1 faithfully reproduces the experimental data and thus can serve as an accurate standard curve.

Figure 4 was deliberately drawn as a double-logarithmic plot. In this presentation, the local slopes of the standard curve represent the rate of relative change in $\Delta D /-\Delta f(\mathrm{~d}(\Delta D /-\Delta f) /(\Delta D /-\Delta f)=\ln (\Delta D /-\Delta f))$ as a function of relative change in HA size $\left(\mathrm{d} n_{\mathrm{ds}} / n_{\mathrm{ds}}=\ln n_{\mathrm{ds}}\right)$, and are an effective measure of size sensitivity of the $\Delta D /-\Delta f$ ratio. The slope $\alpha=\mathrm{d} \ln (\Delta D /-\Delta f) / \mathrm{d} \ln n_{\mathrm{ds}}$ is largest $(\alpha \approx 1.0)$ for oligosaccharides up to $n_{\mathrm{ds}}=10$ and for polysaccharides around $n_{\mathrm{ds}} \approx 10^{3}$, and the method therefore is most sensitive in these size ranges. For intermediate sizes, the size sensitivity is somewhat reduced (down to $\alpha \approx 0.2$ for $n_{\mathrm{ds}} \approx 30$ ), and above $n_{\mathrm{ds}} \approx 1300$ (or $M_{\mathrm{w}} \approx 500 \mathrm{kDa}$ ) it is virtually lost $(\alpha \approx 0$ ).

The size resolution of our standard curve can be estimated from the slopes $\alpha$ and the resolution of the $\Delta D /-\Delta f$ ratio, which is represented by the standard deviation across multiple experiments. Analysis of the data indicates a resolution of better than $10 \%$ up to $n_{\mathrm{ds}} \approx 1300$, with the exception of the smallest HA oligosaccharide $\left(n_{\mathrm{ds}}=2\right)$ where the resolution is $17 \%$ (Figure S5).

Our QCM-D setup monitors changes in resonance frequency and dissipation at higher overtones $(i \geq 5)$, in addition to $i=3$. Comparative analysis (Figure $\mathbf{S 5}$ shows results for $i=3,5$ and 7) revealed that the size sensitivity of $\Delta D /-\Delta f$ was broadly similar, albeit reduced for the largest $\mathrm{HA}$ sizes, for higher overtones. Together, the results demonstrate that $\Delta D /-\Delta f$ values at $-\Delta f=2.5 \mathrm{~Hz}$ for $i=3$ provide a robust and effective discrimination for HA sizes up to $~ 500 \mathrm{kDa}$.

\subsection{The standard curve for sizing HA can also be used for other GAG types}

The standard curve in Figure $\mathbf{4}$ (red line) was established exclusively with size-defined HA. Is this curve also representative for other GAG types? All other GAG types share similar basic disaccharide subunits (i.e., a uronic acid linked to a hexosamine) and hydrodynamic properties with HA to merit a direct comparison. To address this question, we probed size-defined preparations of other GAG types.

As other examples of GAG polysaccharides, we used heparosan (Hep-b $100 \mathrm{kDa}$ and $307 \mathrm{kDa}$ ) and chondroitin (CO-b $276 \mathrm{kDa}$ ) (see Figure S6 for time-resolved QCM-D data and parametric plots of $\Delta D /-\Delta f v s$. $-\Delta f$ ). These regular polysaccharides recapitulate the basic monosaccharide sequences of heparan sulfates/heparin 
bioRxiv preprint doi: https://doi.org/10.1101/2022.02.28.482386; this version posted March 1, 2022. The copyright holder for this preprint made available under aCC-BY-NC-ND 4.0 International license.

(except for a potential epimerisation of GIcA into IdoA; Figure $\mathbf{1 b}$ ) and chondroitin sulfates, respectively, but are the unsulfated biosynthetic precursors. These carbohydrates thus possess a similar linear structure and the same charge density as HA (i.e., one charge per disaccharide), which makes them ideally suited to probe the impact of potential variations of the polysaccharide 'backbone', such as intrinsic chain flexibility, on the $\Delta D /-\Delta f$ ratio. Figure 4 shows that the $\Delta D /-\Delta f$ ratios (at $-\Delta f=2.5 \mathrm{~Hz}$ ) for Hep-b (half-filled orange circles at $n_{\mathrm{ds}}=250$ and 768 , respectively) and CO-b (half-filled dark yellow circle at $n_{\mathrm{ds}}=690$ ) are close to the values for HA-b of similar size, indicating that the standard curve of the defined quasi-monodisperse HA provides a suitable proxy to size nonsulfated GAG polysaccharides other than HA.

As oligosaccharides, we used heparan sulfate preparations of 3, 4, 5 or 6 disaccharides (see Figure $\mathbf{S 6}$ for time-resolved QCM-D data and parametric plots). These oligosaccharides were isolated to monodispersity from an enzymatic digest of heparan sulfate with an average of 1.4 sulfates per disaccharide unit [9], yet are variable in their level and pattern of sulfation. Figure 4 shows that the $\Delta D /-\Delta f$ ratios for most of the HS-b oligosaccharides (half-filled violet circles) are close to the HA-b standard curve. The $\Delta D /-\Delta f$ ratio for the smallest HS oligosaccharide was slightly lower than the interpolated HA data, but overall it appears that the relation of the $\Delta D /-\Delta f$ ratio to size (at $150 \mathrm{mM} \mathrm{NaCl}$ ) is not substantially impacted by sulfation for oligosaccharides. Taken together, these findings suggest that the standard curve established with HA can be applied to determine the size of non-sulfated GAGs of any type, and also of sulfated GAG polysaccharides.

\subsection{Charge-mediated repulsion between GAG chains also affects the QCM-D response, but this effect is small at $150 \mathrm{mM} \mathrm{NaCl}$}

For polysaccharides, it was impossible to directly probe the effect of sulfation on the $\Delta D /-\Delta f$ ratio because we did not have size-defined sulfated GAG polysaccharides available. Recognising that the main effect of sulfation on GAG morphology is due to an increased charge, we explored varying the $\mathrm{NaCl}$ concentration in our experiments as an indirect way to assess the effect of GAG sulfation on the $\Delta D /-\Delta f$ ratio. All GAGs are negatively charged at neutral pH owing to the carboxyl groups (one per each disaccharide for all GAGs), and for sulfated GAGs the sulfation contributes a substantial number of additional chargeable groups: up to three per each disaccharide, depending on GAG type and degree of sulfation (Figure 1b). Whilst added charges on the GAGs are expected to increase the repulsion between GAG chains, this effect can be counteracted by increasing the solution's ionic strength. To test how GAG charge impacts the sensing of GAG brushes by QCM-D, we thus probed responses of brushes made from size-defined HA-b to low $(0 \mathrm{mM})$ and high $(1000 \mathrm{mM}) \mathrm{NaCl}$ concentrations whilst maintaining the $\mathrm{pH}$ at 7.4 with $10 \mathrm{mM}$ HEPES. Whilst we expect the repulsion between GAG chains to be strongly enhanced at $0 \mathrm{mM} \mathrm{NaCl}$, all charge effects on GAG morphology are effectively eliminated at $1 \mathrm{M} \mathrm{NaCl}[18,28]$.

These tests were performed at the end of each experiment following HA-b brush formation in $150 \mathrm{mM}$ $\mathrm{NaCl}$ (see Figure 1c, >130 min, for an example, and Figure $\mathbf{S 2}$ for a complete set of QCM-D data covering all HA sizes). A set of control experiments were required to ascertain that the HA films retain their brush morphology and integrity upon transient exposure to high and low salt conditions. Experiments with non-biotinylated $\mathrm{HA}$ (273 kDa; Figure S1) confirmed that the SAv-on-SLB surface remained inert to HA binding and that HA-b was surface-bound exclusively via the reducing-end biotin tag, under all tested salt conditions. QCM-D signals also fully recovered upon return to $150 \mathrm{mM} \mathrm{NaCl}$ for most HA brushes (Figure S2). Notable exceptions were dense brushes made of intermediate HA sizes (i.e., 13 and $38 \mathrm{kDa}$, and to a minor extent also $58 \mathrm{kDa}$ ), where low salt induced so much swelling and pressure within the brush that it promoted the release of a fraction of the anchored HA chains (see Figure $\mathbf{S 7}$ for a detailed analysis of this effect). When comparing data over a range of salt concentrations, we ascertained that QCM-D responses to salt changes were not affected by changes in HA grafting density. Further control experiments were conducted on bare SAv-on-SLB surfaces (Figure 1c and Figure S2, lines with stars) to quantify the effect of salt changes on the QCM-D response that are not related to HA but arise from the sensitivity of the QCM-D to changes in solution viscosity and density upon variations of the $\mathrm{NaCl}$ 
bioRxiv preprint doi: https//doi.org/10.1101/2022.02 28.482386; this version posted March 1, 2022. The copyright holder for this preprint (which was not certified by peer review) is the author/funder, who has granted bioRxiv a license to display the preprint in perpetuity. It is made available under aCC-BY-NC-ND 4.0 International license.

concentration. These effects from changes in solution properties were subtracted from the QCM-D responses obtained with HA brushes to calculate the net effect due to the impact of ionic strength variations on the HA brushes (see Supplementary Methods for details).

Figure 5 compares the net $\Delta D /-\Delta f$ ratios for $\mathrm{HA}$ brushes for $0 \mathrm{mM}, 150 \mathrm{mM}$ or $1000 \mathrm{mM} \mathrm{NaCl}$ across all HA sizes. Note that we here consider the $\Delta D /-\Delta f$ ratios at maximal surface coverage; it would be challenging to test the effect of salt at low surface coverage (- $\Delta f$ between 2 to $3 \mathrm{~Hz}$, as established in Figure 4$)$ because of excessively large experimental errors associated with the buffer exchanges relative to the QCM-D response for $\mathrm{HA}$ binding. Clear differences are noticeable when comparing the data for $0 \mathrm{mM}$ to $1000 \mathrm{mM} \mathrm{NaCl}$, demonstrating that the $\Delta D /-\Delta f$ ratio in general is sensitive to GAG charge in addition to GAG size. Effects are most obvious for the HA polysaccharides, where the $\Delta D /-\Delta f$ ratio increases with decreasing ionic strength, likely due to brush swelling (see Figure $\mathbf{S 2}$, legend, for a related analysis of the complex trends observed for $\Delta D$ and $\Delta f$ individually). This tendency appears to reverse for GAG oligosaccharides, although the effect is relatively small and it is unclear if it is significant considering the experimental errors.

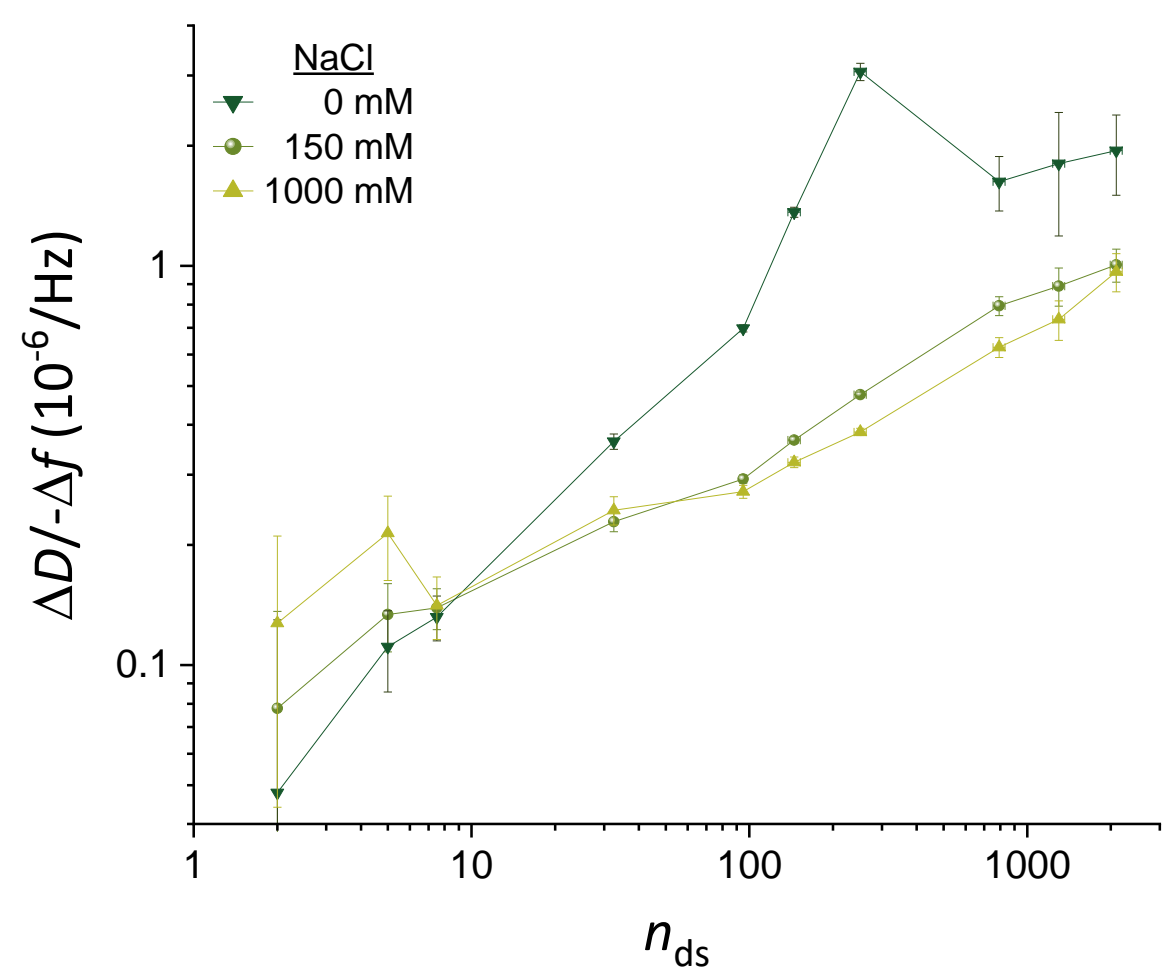

Figure 5. Effect of ionic strength on $\Delta D /-\Delta f$ ratios. Double logarithmic plot of $\Delta D /-\Delta f(i=3)$ as a function of the mean number of disaccharides ( $n_{\mathrm{ds}}$ ) per $\mathrm{HA}$ chain, for $\mathrm{NaCl}$ concentrations of $0 \mathrm{mM}, 150 \mathrm{mM}$ and $1000 \mathrm{mM}$ (as indicated with symbol and colour code). Representative data for one experiment per HA size are shown. The mean values represent the $\Delta D /-\Delta f$ ratio measured at high GAG surface densities (i.e., the maximal surface densities that were attained in the experiments and stable at $0 \mathrm{mM} \mathrm{NaCl}$; see Figure $\mathbf{S 2}$ for original data). The error bars account for baseline drifts during GAG binding. In the cases of 0 and $1000 \mathrm{mM} \mathrm{NaCl}$, solution effects on the QCM-D response (i.e., owing to the effect of salt on solution density and/or viscosity) needed to be corrected for with the aid of control data, and uncertainties associated with this correction are also included in the error bars (see Figure 1c and Supplementary Methods for details).

The $\Delta D /-\Delta f$ ratios at $150 \mathrm{mM}$, on the other hand, were comparable to $1000 \mathrm{mM} \mathrm{NaCl}$ within experimental error for small HA chains $(\leq 38 \mathrm{kDa})$ as well as for the largest HA chains ( $\geq 520 \mathrm{kDa})$, and only moderately increased (by up to $27 \%$ ) for intermediate HA sizes $(58,100$ and $317 \mathrm{kDa}$ ). The relatively small differences demonstrate that charge effects are largely screened at $150 \mathrm{mM} \mathrm{NaCl}$ and that $\Delta D /-\Delta f$ values at 150 
bioRxiv preprint doi: https://doi.org/10.1101/2022.02.28.482386; this version posted March 1, 2022. The copyright holder for this preprint (which was not certified by peer review) is the author/funder, who has granted bioRxiv a license to display the preprint in perpetuity. It is made available under aCC-BY-NC-ND 4.0 International license.

$\mathrm{mM} \mathrm{NaCl}$ primarily report on GAG size, although some caution is advised for GAG sizes in the range of many tens of $\mathrm{kDa}$ to a few hundred $\mathrm{kDa}$. This finding provides further support to the use of $150 \mathrm{mM} \mathrm{NaCl}$ (as already used in Figure 4) for GAG sizing applications, including for sulfated GAG polysaccharides.

\subsection{Application examples for GAG sizing}

We present a few simple examples to illustrate the benefits of the developed method to determine the mean molecular mass of surface-grafted GAGs. In most cases of practical relevance, GAG samples are derived from natural sources and purified to varying degrees. With the exception of oligosaccharides, purified GAGs from natural sources (i.e., animal tissues and bacterial cells) retain a substantial degree of polydispersity (illustrated in Figure S8) even with the most advanced current size fractionation methods. Thus, we explored if the mean size of surface-grafted GAGs faithfully recapitulate the size distribution of the original GAG solution from which a GAG brush is being formed.

We tested this with a solution of polydisperse HA with a mean molecular mass of $357 \mathrm{kDa}$ according to the manufacturer (Table 2). Gel electrophoresis confirmed the broad dispersity of this HA reagent (Figure S8a and Figure 6b) after biotinylation at the reducing end, although the most abundant size appeared to be somewhat higher ( 500 kDa); half-maximal staining intensities above background were reached at approximately $200 \mathrm{kDa}$ on the lower end, and $>800 \mathrm{kDa}$ at the higher end (the gel did not allow reliable determination of the upper limit). In contrast, the $\Delta D /-\Delta f$ ratio obtained with this sample (Figure 6a; see Figure S9a for the time-resolved QCM-D data) provided an effective HA mean size on the surface of $150 \pm 40 \mathrm{kDa}$ (Figure 6b), through comparison with the standard curve (Figure 4 and Equation 1). This example illustrates that the surface bound technology can unintentionally favour the binding of smaller GAGs in a polydisperse sample leading to the mean GAG size on the surface being substantially lower than in solution. One likely reason for preferential binding of smaller GAG molecules with lower hydrodynamic radius is their faster diffusion to the surface. In addition, the size skewing will be exacerbated by the barrier properties of the forming GAG brush: the barrier will be most pronounced for the longest chains in the GAG pool and the brush thus effectively sieves out shorter chains for surface binding. The latter effect should be particularly pronounced for large GAGs ( $\geq 100$ kDa; see Section 4.3 for a detailed discussion), and we propose that this explains the more than two-fold reduction in effective mean size upon surface anchorage for the large polydisperse HA.
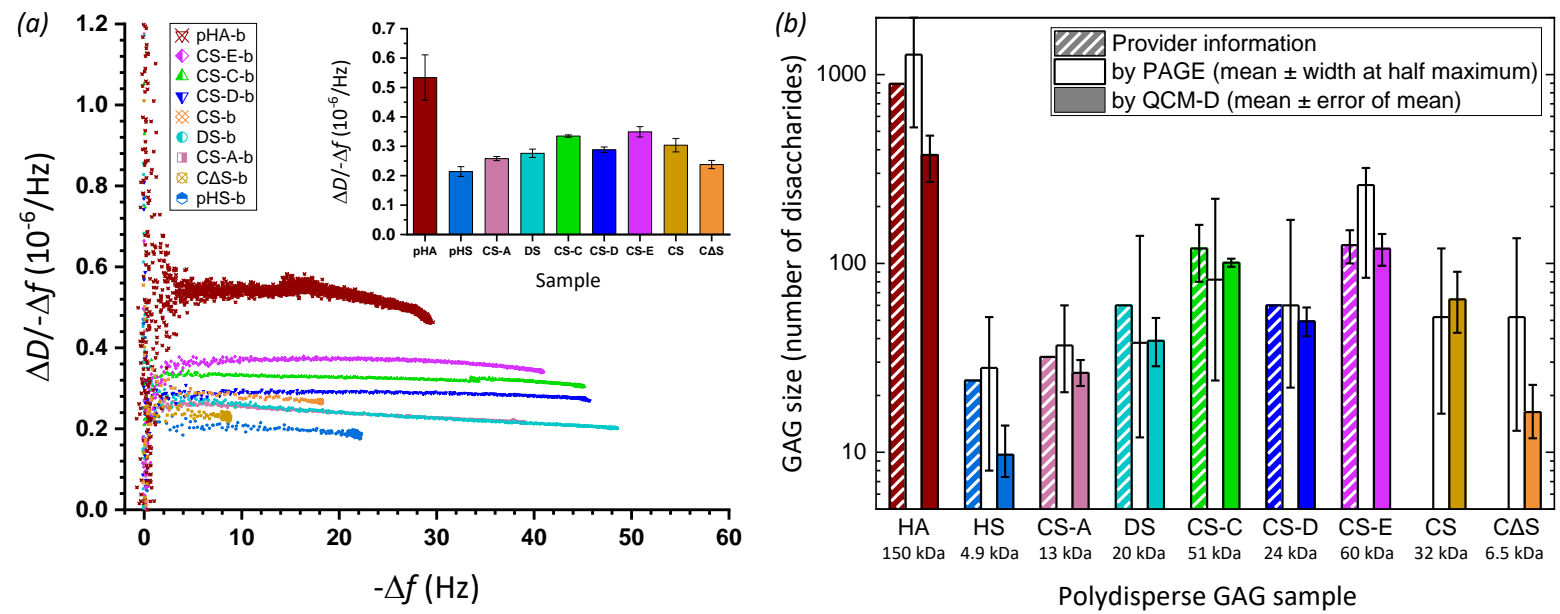

Figure 6. Application examples of GAG sizing. (a) Plot of the $\Delta D /-\Delta f$ ratio vs. $-\Delta f(i=3)$ for selected polydisperse GAG-b polysaccharide preparations of HA and other GAG types (chondroitin sulfate - CS, CS-A, CS-C, CS-D and CS-E, chemically desulfated CS - C $\Delta S$, dermatan sulfate - DS, heparan sulfate - HS; symbols and colour codes as indicated). Original QCM-D data are shown in Figure S9. The inset shows the $\Delta D /-\Delta f$ values at $-\Delta f=2.5 \mathrm{~Hz}$, as mean \pm standard deviations for $-\Delta f$ values ranging between 2 and $3 \mathrm{~Hz}$. (b) Comparison of the effective size (in number of disaccharides $n_{\mathrm{ds}}$ ) of surface-grafted GAG-b polysaccharides (as determined by QCM-D; filled bars) with the effective size distribution of GAG-b polysaccharides in solution (as determined by PAGE; unfilled bars) 
bioRxiv preprint doi: https://doi.org/10.1101/2022.02 28.482386; this version posted March 1, 2022. The copyright holder for this preprint (which was not certified by peer review) is the author/funder, who has granted bioRxiv a license to display the preprint in perpetuity. It is made available under aCC-BY-NC-ND 4.0 International license.

and the size estimates of the original GAGs given by the provider (bars with diagonal lines; taking disaccharide masses to be $400 \mathrm{Da}$ for HA, and $500 \mathrm{Da}$ for all sulfated GAGs). To calculate GAG sizes from QCM-D data, the $\Delta D /-\Delta f$ values at $-\Delta f=2.5 \mathrm{~Hz}$ of the polydisperse GAG-b preparations were compared with the standard curve (Figure 4 and Equation 1). To calculate the effective size distribution from PAGE data, the migration distances of the peak intensity and the half-maximal intensities above background were compared to the migration distances of size-defined HA standards (Figure S8). The effective molecular masses of surface-grafted GAGs (in $\mathrm{kDa}$ ) are given below the GAG names, and were derived from $n_{\mathrm{ds}}$ with disaccharide masses of $400 \mathrm{Da}$ for $\mathrm{HA}$ and $\mathrm{C} \Delta \mathrm{S}$, and $500 \mathrm{Da}$ for all sulfated GAGs.

To test if the developed method could size other GAGs with shorter lengths, we also analysed several sulfated polydisperse GAG polysaccharides from commercial sources, including heparan sulfate (HS), dermatan sulfate (DS), and chondroitin sulfate (CS) including preparations purified to varying degrees of sulfation (CS-A, CS-C, CS-D and CS-E) (Table 2). The QCM-D results (Figure S9 and Figure 6a) show that the trends for the calculated mean molecular masses are in good agreement with company estimates (Figure $6 \mathbf{b}$ ) and PAGE analyses (Figure S8b-c), and thus confirm that the established standard curve (Figure 4) can also be used to determine the effective mean size of sulfated polydisperse GAGs on surfaces. A general tendency towards lower mean GAG sizes on surfaces can be observed, but the differences for the sulfated GAGs are typically less pronounced than for the polydisperse HA (Figure $6 \mathbf{b}$ ). Since the sulfated GAGs were $<100 \mathrm{kDa}$, steric hindrance by the forming brush should be negligible, and the reduction in mean size of these GAGs on surfaces is most likely due to faster diffusive transport of smaller molecules. An unusually large decrease in mean size is noticeable for the HS sample, and we suggest that this might be due to the exceptionally large size distribution of this particular sample: in PAGE, the pHS sample spread all the way to the bottom of the gel (Figure S8b).

Lastly, we demonstrate that the method can be uniquely used to analyse how chemical treatment affects GAG size. In this particular example, the chondroitin sulfate (CS) preparation was chemically treated to produce desulfated chondroitin sulfate ( $C \Delta S$; see Supplementary Methods for details). Comparative QCM-D analysis of the sample before and after chemical modification (and after the required conjugation with biotin at the reducing end; Figure $\mathbf{5 9} \mathbf{b}$ and Figure 6a; orange diamond and yellow circle with crosses, respectively) revealed that the desulfation process significantly reduced the mean GAG size (Figure $6 \mathbf{6 b}$ ), revealing undesired degradation in the process. Of note, this type of comparative analysis is challenging with gel electrophoresis because the change in charge upon desulfation substantially affects the migration behaviour in addition to the effect of GAG size. Indeed, the $C \Delta S$ and CS samples were virtually indistinguishable when analysed by gel electrophoresis (Figure S8c), most likely due to a coincidental cancellation of charge and size effects on the migration rate. 


\section{Discussion}

\subsection{Workflow and benefits of GAG sizing on surfaces by QCM-D}

Using a large spectrum of size-defined HA polymers, we have established a method to quantify the mean size of GAGs grafted with one end to a planar surface. The method relies on QCM-D as the sole analysis technique, and exploits the monotonic increase of the $\Delta D /-\Delta f$ ratio with GAG size. The standard curve of $\Delta D /-\Delta f$ vs. GAG size, established here with $\mathrm{HA}$ in $150 \mathrm{mM} \mathrm{NaCl}$ for the third overtone at a set frequency shift of $-\Delta f=2.5$ $\mathrm{Hz}$ (Figure 4 and Equation 1), provides good size sensitivity up to $500 \mathrm{kDa}$ and can be applied for $\mathrm{HA}$ as well as other GAG types (Figures 4 and 6). This technique is especially useful for its ability to measure the mean GAG size directly at surfaces, in particular for large polydisperse GAGs, as the surface-attachment process can substantially modulate the size distribution, causing smaller chains to preferentially bind compared to the original size distribution in solution (Figure 6).

Figure 7 recapitulates the main steps involved in GAG sizing on surfaces, which comprises: (i) conjugation of an anchor tag (here biotin) to one end (here the reducing end) of the GAG chains, (ii) monitoring of GAG grafting to a planar and quasi-rigid surface by QCM-D (at $150 \mathrm{mM} \mathrm{NaCl}$ ), (iii) determining the timeaveraged $\Delta D /-\Delta f$ ratio at $-\Delta f=2.5 \mathrm{~Hz}$ from the parametric $\Delta D /-\Delta f v s$. $-\Delta f$ plot $(i=3)$, and (iv) determination of the mean GAG size with the aid of the standard curve (Figure 4 and Equation 1). We note that only the GAG binding data up to $\Delta f=-3 \mathrm{~Hz}$ are required for the GAG sizing to work. The GAG incubation process therefore can be shortened compared to the example shown in Figure 7 thus reducing time and sample where this is desirable. An extended binding range though has the benefit of permitting further quality control, as the trends in the parametric $\Delta D /-\Delta f v s$. $-\Delta f$ plot can be compared with size-defined standards.

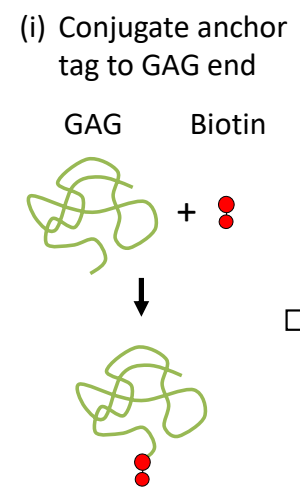

$$
\begin{aligned}
& \text { (ii) Monitor GAG } \\
& \text { grafting by QCM-D }
\end{aligned}
$$

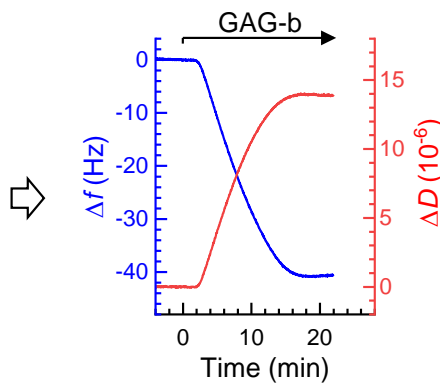

(iii) Establish parametric plot and determine $\Delta D /-\Delta f$ at $-\Delta f \approx 2.5 \mathrm{~Hz}$

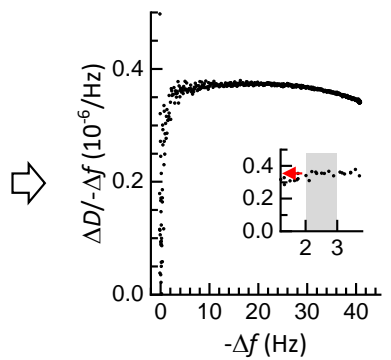

(iv) Determine mean GAG size with standard curve

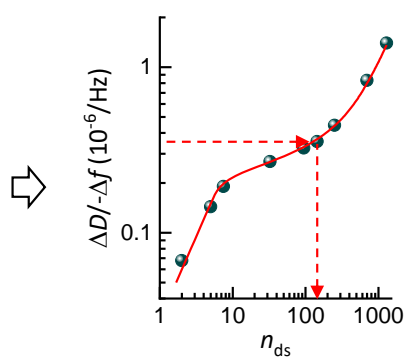

Figure 7. Flow diagram of the process of sizing surface-grafted GAGs. The four main steps are illustrated.

We expect that the here-established method will be most useful for the characterisation of GAG-based surface coatings. Benefits in this regard are that the GAG size is measured directly at the surface, and that the required data can be obtained non-destructively whilst monitoring GAG film formation by QCM-D. The latter is useful (e.g., for quality control) whenever GAG-functionalised surfaces are to be used further, e.g., for biomolecular interaction studies by QCM-D or other 'solid-phase' analysis techniques such as surface plasmon resonance or ellipsometry.

This QCM-D method should be of particular interest for the biophysical characterisation of GAGs isolated from tissues. Selective biotinylation of GAGs at their reducing end is well established [6], the amounts of GAG required for size analysis are relatively small (a few $\mu \mathrm{g}$ or less), and further on-surface analysis is possible to probe for selective interactions with GAG-binding proteins for glycobiological analyses. GAGs have also been widely exploited for biomedical applications such as implant coatings, biomaterial scaffolds and as nanoparticles for drug delivery. The insights and data from this study should be useful for improved characterisation of such 
bioRxiv preprint doi: https://doi.org/10.1101/2022.02.28.482386; this version posted March 1, 2022. The copyright holder for this preprint (which was not certified by peer review) is the author/funder, who has granted bioRxiv a license to display the preprint in perpetuity. It is made available under aCC-BY-NC-ND 4.0 International license.

materials, and for the design and manufacture of GAG-based coatings with improved performance for tissue engineering and medical device applications.

\subsection{Sensitivity of the here-established method of GAG analysis}

In Section 3.4, we established the slope $\alpha$ of the standard curve as a simple way to assess the size sensitivity of our GAG sizing method. Similarly, from the logarithmic presentation in Figure $\mathbf{5}$, it can be concluded that the HA size sensitivity improves at low ionic strength for oligosaccharides and smaller polysaccharides up to $58 \mathrm{kDa}\left(n_{\mathrm{ds}} \approx 150\right)$. Although this benefit comes at the expense of a complete loss in size sensitivity for HA >58 $\mathrm{kDa}$, this example illustrates that tuning of ionic strength could potentially be exploited to optimize GAG sizing sensitivity for certain applications.

Moreover, with the QCM-D response being sensitive to GAG size and GAG charge (Figure 5), it is conceivable that a screen of $\Delta D /-\Delta f$ over a range of ionic strengths could in the future be employed to analyse the (mean) charge in addition to the (mean) size of surface-grafted GAGs. Such a methodology would benefit from a wider range of size- and charge-defined GAGs to establish a suitable 'two-dimensional' standard than what is currently accessible, although the compensation of charge and ionic strength $[18,28]$ can potentially also be exploited.

\subsection{A model to explain the complex shape of the standard curve}

The shape of the here-established standard curve (Figure 4) is remarkably complex. Considering again a double logarithmic plot of the HA data (Figure 8a), four size-sensitivity regimes can be discerned. Regimes I and II are described by distinct power laws (Figure 8a, dashed red lines with slopes indicated), with rather welldefined slopes (i.e., powers) of 1.0 and 0.2 , respectively. Regime IV may be the start of a plateau (power $=0$ ) or close to a maximum (as more clearly seen with higher overtones, see Figure S5). In regime III, the sensitivity of $\Delta D /-\Delta f$ for HA size is not described by a power law but instead gradually increases, and clearly is higher than in the neighbouring regimes II and IV.

What are the physical mechanisms giving rise to four distinct regimes? A comprehensive theoretical model that links GAG size to $\Delta D /-\Delta f$ ratio remains elusive. However, the location of the boundaries between regimes hints at the regimes reflecting differences in HA chain conformation, as illustrated in Figure $\mathbf{8 b}$. Specifically, the transition between regimes I and II is located at 7 disaccharides, equivalent to a contour length of $L_{c} \approx 7 \mathrm{~nm}$. This value is comparable to the persistence length of $\mathrm{HA}\left(L_{\mathrm{p}, \mathrm{HA}} \approx 4 \mathrm{~nm}\right)$, implying that rigid $\left(L_{c}<L_{\mathrm{p}}\right)$ and semi-flexible $\left(L_{c} \approx L_{\mathrm{p}}\right)$ HA chains are probed in regime $\mathrm{I}$, whereas flexible $\left(L_{c}>L_{\mathrm{p}}\right)$ HA chains are probed in all other regimes. Tsortos et al. [27] have previously presented an analysis of $\Delta D /-\Delta f$ values for one-end grafted double-stranded DNA (dsDNA), which is reproduced in Figure 8a (inset) for comparison. Although other aspects of the curve shape for dsNA are different, we note a similar transition from a stronger size dependence to a weaker size dependence at approximately $80 \mathrm{~nm}$, again slightly larger than the persistence length of dsDNA $\left(L_{\mathrm{p}}\right.$, dsDNA $\left.\approx 50 \mathrm{~nm}\right)$. Tsortos et $a l$. [27] further suggested a theoretical model for the regime of rigid and semiflexible chains that links the polymer shape (parametrised as intrinsic viscosity) to the $\Delta D /-\Delta f$ values. With appropriate re-scaling based on this model, to account for differences in the mass per unit length and the diameter of the two polymers, we find that the data for HA and dsDNA superimpose rather well in the rigid chain regime (Figure S10). Taken together, these findings suggest that the transition between regime I (high sizesensitivity) and regime II (lower size sensitivity) is a general feature of polymer brushes and occurs when the contour length roughly matches the persistence length.

The origin of the transition between regimes II and III is less obvious. We propose that it relates to the onset of repulsion between grafted chains. As the chain size increases, the radius of gyration (which defines the mean size of the random coil formed by flexible HA chains in solution; $R_{\mathrm{g}}$ ) also increases. HA chains will retain their characteristic random coil conformation upon surface grafting as long as the radius of gyration is inferior 
to the mean anchor spacing $\left(d_{\mathrm{rms}} \geq R_{\mathrm{g}}\right)$, but inter-chain repulsion at $d_{\mathrm{rms}}<R_{\mathrm{g}}$ leads to chain stretching and film thickness changes. The first data point clearly departing from power 0.2 behaviour corresponds to an HA size of 250 disaccharides $\left(L_{c} \approx 250 \mathrm{~nm} ; M_{\mathrm{w}} \approx 100 \mathrm{kDa}\right.$ ). The radius of gyration for an HA chain of $250 \mathrm{~nm}$ contour length is $R_{\mathrm{g}} \approx 21 \mathrm{~nm}$ [29]. We do not know what the exact anchor spacing of such an HA chain would be at $\Delta f=-2.5 \mathrm{~Hz}$, but in light of attainable anchor spacings for very short HA chains ( $d_{\mathrm{rms}} \approx 5 \mathrm{~nm}$ for oligosaccharides) and very long HA chains ( $d_{\mathrm{rms}}>50 \mathrm{~nm}$ for HA $838 \mathrm{kDa}$; see section 3.2), a value in the range of $20 \mathrm{~nm}$ (i.e., consistent with a transition from random coil to brush conformation at this HA size) appears entirely reasonable.

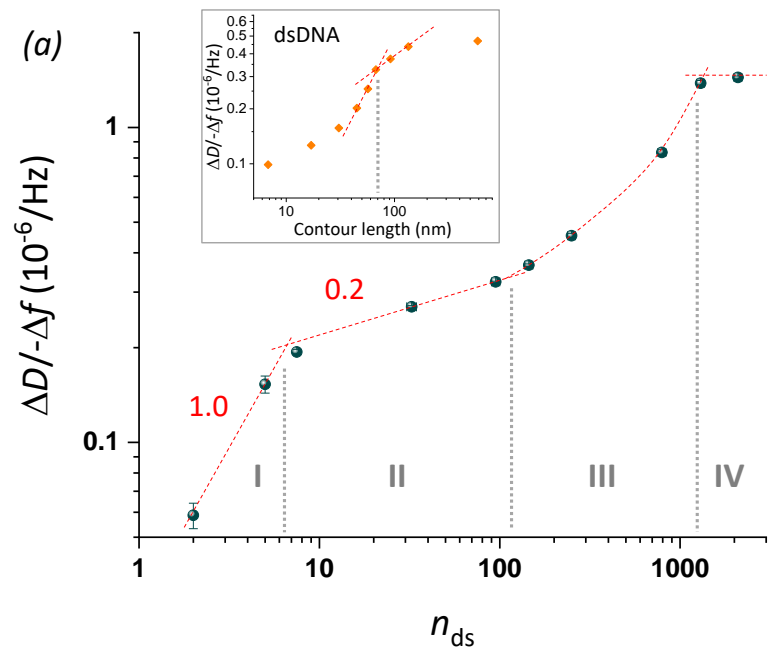

(b)

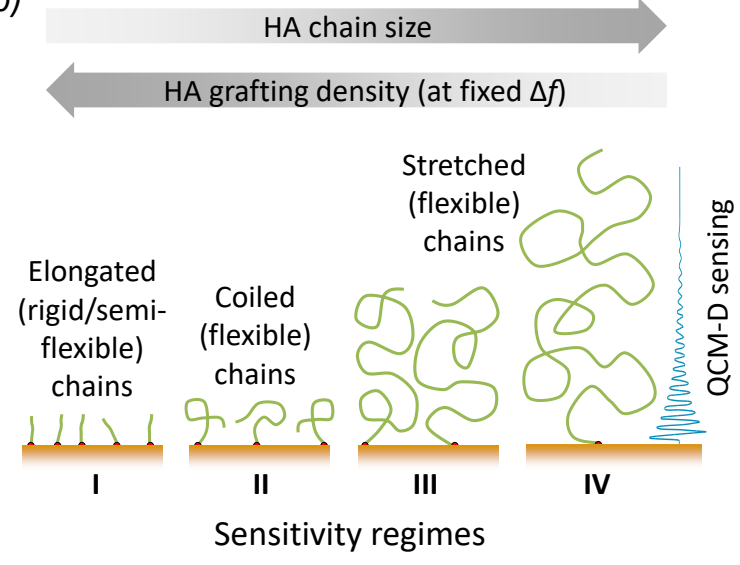

Figure 8. Sensitivity regimes of HA and underpinning mechanisms. (a) Double-logarithmic plot of the $\Delta D /-\Delta f$ ratio $(i=3)$ at low HA surface density $(-\Delta f=2.5 \mathrm{~Hz})$ as a function of the mean number of disaccharides, $n_{\mathrm{ds}}$. Data for HA (blue spheres with error bars) are reproduced from Figure 4. Sensitivity regimes I to IV are separated by vertical grey dotted lines. Regimes I and II are discerned by their distinct power-law dependencies (red dashed lines with slope illustrate the approximate power); regime III does not obey a power law (red curved dashed line illustrates the trend) and regime IV is close to a plateau/maximum (indicated by a horizontal line). The inset shows equivalent data for dsDNA extracted from Figure 3 of Ref. [27], with two selected power law dependencies (dashed red lines). (b) Illustration of the proposed model to explain the observed sensitivity regimes. Both HA chain size and grafting density (which decreases with increasing chain size at the set $-\Delta f=2.5$ $\mathrm{Hz}$ ) influence chain conformation, and distinct chain conformations are associated with sensitivity regimes I, II and III; ultimately, chain stretching exceeds the QCM-D sensing depth leading to a $\Delta D /-\Delta f$ maximum and vanishing size sensitivity in regime IV.

Last but not least, the transition between regimes III and IV is likely defined by the limited sensing depth of QCM-D. The sensing depth in water (as well as ultrasoft HA films) is on the order of a few $100 \mathrm{~nm}$ [30, 31] which is rather close to the radius of gyration of the largest HA chains ( $R_{\mathrm{g}} \approx 75 \mathrm{~nm}$ for HA $838 \mathrm{kDa}$ ); therefore, even with only moderate chain stretching the HA brush thickness can readily exceed the QCM-D sensing depth.

Taken together, the different HA conformation regimes combined with the limited QCM-D sensing depth (Figure 8b) provide a first plausible explanation for the complex shape of the standard curve and the four distinct sensitivity regimes. In the future, further analysis with complementary techniques to directly measure HA grafting densities and film thicknesses may help to confirm and refine this model, and the insight gained could be exploited to further maximise size sensitivity for selected size ranges. 
bioRxiv preprint doi: https://doi.org/10.1101/2022.02.28.482386; this version posted March 1, 2022. The copyright holder for this preprint (which was not certified by peer review) is the author/funder, who has granted bioRxiv a license to display the preprint in perpetuity. It is made available under aCC-BY-NC-ND 4.0 International license.

\section{Conclusions}

We have established an on-surface technique, based on QCM-D, to quantify the mean size of one-end grafted GAGs. The standard curve of $\Delta D /-\Delta f$ vs. GAG size, represented by Equation 1, enables determination of the effective mean GAG size up to $500 \mathrm{kDa}$. The method is accurate for unsulfated GAGs such as HA, and also provides robust size estimates for sulfated GAGs such as HS and CS, with a typical resolution below $10 \%$. By systematically analysing GAG brushes as a function of GAG size and type, this work has also provided new insight into basic physical properties of such brushes, such as the kinetics of GAG brush formation, the stability of GAG brushes, and how GAG conformation in GAG brushes is sensed by QCM-D. We have illustrated the importance of measuring the mean GAG size directly at surfaces, in particular for large polydisperse GAGs, as the surfaceattachment process can substantially reduce the mean size compared to the mean size of the GAG pool in solution. The GAG sizing method will be most useful for the characterisation of GAG-based surface coatings, and should be of particular interest for the biophysical characterisation of GAGs isolated from tissues, and for the design and quality control of GAG-based coatings with improved performance for tissue engineering and medical device applications.

\section{Acknowledgements}

We thank Anne Geert Volbeda and Jeroen Codee for kindly providing HAdp15-b, Hugues Lortat-Jacob for kindly providing HS polysaccharides and oligosaccharides for biotinylation, and Dhruv Thakar for biotinylating the polydisperse HA and HS polysaccharides, and the HS oligosaccharides.

This work was supported by an Oklahoma Center for Advancement of Science and Technology grant (HR18-104, to PLD), a Long Duration Visitor Grant from Labex Tec21 (ANR-11-LABX-0040, to DD and RPR), a Research Grant from the BBSRC, UK (BB/T001631/1, to RPR), the Leverhulme Trust (RPG-2018-100, to JCFK and RPR), an EPSRC CDT project funding (EP/L014823/1, to LS and JCFK), and the Center of Reconstruction Neuroscience NEURORECON (CZ.02.1.01/0.0/0.0/15_003/0000419 to JCFK).

\section{Author contributions}

SS designed experiments, collected and analysed data, and drafted the original manuscript. LS conceived the study, designed experiments, and collected and analysed data. AG, DEG, JD and PLD provided essential reagents. LD provided essential reagents and collected data. ARER and XZ collected data. DD analysed data. JCFK and RPR conceived the study, designed experiments, analysed data, drafted the original manuscript, supervised the project and raised funds. All authors contributed to manuscript review and editing.

\section{References}

1. Jing, W., F.M. Haller, A. Almond, and P.L. DeAngelis, Defined megadalton hyaluronan polymer standards. Anal Biochem, 2006. 355(2): p. 183-8.

2. Jing, W., J.W. Roberts, D.E. Green, A. Almond, and P.L. DeAngelis, Synthesis and characterization of heparosan-granulocyte-colony stimulating factor conjugates: a natural sugar-based drug delivery system to treat neutropenia. Glycobiology, 2017. 27(11): p. 1052-1061.

3. Jing, W. and P.L. DeAngelis, Analysis of the two active sites of the hyaluronan synthase and the chondroitin synthase of Pasteurella multocida. Glycobiology, 2003. 13(10): p. 661-71.

4. Jing, W. and P.L. DeAngelis, Synchronized chemoenzymatic synthesis of monodisperse hyaluronan polymers. J Biol Chem, 2004. 279(40): p. 42345-9.

5. Tracy, B.S., F.Y. Avci, R.J. Linhardt, and P.L. DeAngelis, Acceptor specificity of the Pasteurella hyaluronan and chondroitin synthases and production of chimeric glycosaminoglycans. J Biol Chem, 2007. 282(1): p. 337-44.

6. Thakar, D., E. Migliorini, L. Coche-Guerente, R. Sadir, H. Lortat-Jacob, D. Boturyn, O. Renaudet, P. Labbe, and R.P. Richter, A quartz crystal microbalance method to study the terminal functionalization of glycosaminoglycans. Chem Commun (Camb), 2014. 50(96): p. 15148-51. 
bioRxiv preprint doi: https://doi org/10.1101/2022.02.28.482386; this version posted March 1 , 2022. The copyright holder for this preprint (which was not certified by peer review) is the author/funder, who has granted bioRxiv a license to display the preprint in perpetuity. It is made available under aCC-BY-NC-ND 4.0 International license.

7. Dubacheva, G.V., C. Araya-Callis, A. Geert Volbeda, M. Fairhead, J. Codee, M. Howarth, and R.P. Richter, Controlling Multivalent Binding through Surface Chemistry: Model Study on Streptavidin. J Am Chem Soc, 2017. 139(11): p. 4157-4167.

8. Dubacheva, G.V., T. Curk, B.M. Mognetti, R. Auzély-Velty, D. Frenkel, and R.P. Richter, Superselective targeting using multivalent polymers. J Am Chem Soc, 2014. 136(5): p. 1722-1725.

9. Jasnin, M., L. van Eijck, M.M. Koza, J. Peters, C. Laguri, H. Lortat-Jacob, and G. Zaccai, Dynamics of heparan sulfate explored by neutron scattering. Phys Chem Chem Phys, 2010. 12(14): p. 3360-2.

10. Richter, R.P., A. Mukhopadhyay, and A. Brisson, Pathways of lipid vesicle deposition on solid surfaces: a combined QCM-D and AFM study. Biophysical Journal, 2003. 85(5): p. 3035-3047.

11. Richter, R.P., K.K. Hock, J. Burkhartsmeyer, H. Boehm, P. Bingen, G. Wang, N.F. Steinmetz, D.J. Evans, and J.P. Spatz, Membrane-grafted hyaluronan films: a well-defined model system of glycoconjugate cell coats. J Am Chem Soc, 2007. 129(17): p. 5306-7.

12. Baranova, N.S., E. Nileback, F.M. Haller, D.C. Briggs, S. Svedhem, A.J. Day, and R.P. Richter, The inflammation-associated protein TSG-6 cross-links hyaluronan via hyaluronan-induced TSG-6 oligomers. J Biol Chem, 2011. 286(29): p. 25675-86.

13. Bano, F., S. Banerji, M. Howarth, D.G. Jackson, and R.P. Richter, A single molecule assay to probe monovalent and multivalent bonds between hyaluronan and its key leukocyte receptor CD44 under force. Sci Rep, 2016. 6: p. 34176.

14. Alexander, S., Adsorption of chain molecules with a polar head a scaling description. J. Phys. France, 1977. 38(8): p. 983-987.

15. Bhat, R.R., M.R. Tomlinson, T. Wu, and J. Genzer, Surface-Grafted Polymer Gradients: Formation, Characterization, and Applications, in Surface-Initiated Polymerization II, R. Jordan, Editor. 2006, Springer Berlin Heidelberg: Berlin, Heidelberg. p. 51-124.

16. Richter, R.P., N.S. Baranova, A.J. Day, and J.C. Kwok, Glycosaminoglycans in extracellular matrix organisation: are concepts from soft matter physics key to understanding the formation of perineuronal nets? Curr Opin Struct Biol, 2018. 50: p. 65-74.

17. Rubinstein, M. and R.H. Colby, Polymer physics. 2003, Oxford ; New York: Oxford University Press. xi, 440 p.

18. Chen, X. and R.P. Richter, Effect of calcium ions and $\mathrm{pH}$ on the morphology and mechanical properties of hyaluronan brushes. Interface Focus, 2019. 9(2): p. 20180061.

19. Bingen, P., G. Wang, N.F. Steinmetz, M. Rodahl, and R.P. Richter, Solvation effects in the quartz crystal microbalance with dissipation monitoring response to biomolecular adsorption. A phenomenological approach. Anal Chem, 2008. 80(23): p. 8880-90.

20. Richter, R.P., R. Berat, and A.R. Brisson, Formation of solid-supported lipid bilayers: an integrated view. Langmuir, 2006. 22(8): p. 3497-505.

21. Ligoure, C. and L. Leibler, Thermodynamics and kinetics of grafting end-functionalized polymers to an interface. Journal De Physique, 1990. 51: p. 1313-1328.

22. Attili, S. and R.P. Richter, Self-assembly and elasticity of hierarchical proteoglycan-hyaluronan brushes. Soft Matter, 2013. 9(44): p. 10473-10483.

23. Davies, H.S., N.S. Baranova, N. El Amri, L. Coche-Guerente, C. Verdier, L. Bureau, R.P. Richter, and D. Debarre, An integrated assay to probe endothelial glycocalyx-blood cell interactions under flow in mechanically and biochemically well-defined environments. Matrix Biol, 2019. 78-79: p. 47-59.

24. Du, B. and D. Johannsmann, Operation of the quartz crystal microbalance in liquids: derivation of the elastic compliance of a film from the ratio of bandwidth shift and frequency shift. Langmuir, 2004. 20(7): p. 2809-12.

25. Reviakine, I., D. Johannsmann, and R.P. Richter, Hearing what you cannot see and visualizing what you hear: interpreting quartz crystal microbalance data from solvated interfaces. Anal Chem, 2011. 83(23): $p$. 8838-48.

26. Tellechea, E., D. Johannsmann, N.F. Steinmetz, R.P. Richter, and I. Reviakine, Model-independent analysis of QCM data on colloidal particle adsorption. Langmuir, 2009. 25(9): p. 5177-5184.

27. Tsortos, A., G. Papadakis, and E. Gizeli, Shear acoustic wave biosensor for detecting DNA intrinsic viscosity and conformation: a study with QCM-D. Biosens Bioelectron, 2008. 24(4): p. 842-7.

28. Attili, S., O.V. Borisov, and R.P. Richter, Films of end-grafted hyaluronan are a prototype of a brush of a strongly charged, semi-flexible polyelectrolyte with intrinsic excluded volume. Biomacromolecules, 2012. 13(5): p. 1466-1477. 
bioRxiv preprint doi: https://doi.org/10.1101/2022.02.28.482386; this version posted March 1, 2022. The copyright holder for this preprint (which was not certified by peer review) is the author/funder, who has granted bioRxiv a license to display the preprint in perpetuity. It is made available under aCC-BY-NC-ND 4.0 International license.

29. Takahashi, R., S. Al-Assaf, P.A. Williams, K. Kubota, A. Okamoto, and K. Nishinari, Asymmetrical-Flow FieldFlow Fractionation with On-Line Multiangle Light Scattering Detection. 1. Application to Wormlike Chain Analysis of Weakly Stiff Polymer Chains. Biomacromolecules, 2003. 4(2): p. 404-409.

30. Domack, A., O. Prucker, J. Rühe, and D. Johannsmann, Swelling of a polymer brush probed with a quartz crystal resonator. Physical review. E, Statistical physics, plasmas, fluids, and related interdisciplinary topics, 1997. 56(1): p. 680-689.

31. Johannsmann, D., The Quartz Crystal Microbalance in Soft Matter Research. Soft and Biological Matter, ed. R. Piazza, et al. 2015: Springer. 